(Physiologisches Laboratorium in Bonn.)

\title{
Ueber \\ den elementaren Bau des Nervensystems ${ }^{1}$ ). \\ Von
}

Eduard Pfï̈ger.

(Mit 36 Textfiguren.)

\section{Theil I.}

Seit 1858, wo ich meine akademische Laufbahn in Berlin begann, bis heute habe ich jeder Zeit in meinen Vorlesungen die Ansicht vertreten, dass das Nervensystem mit Einschluss der peripherischen Sinneszellen, der Muskeln, der elektrischen Organe, der Drüsen, denen ich jetzt noch gewisse Pigment- und Flimmerzellen beifüge, ein ungeheures Zellennetz, das „animale“, darstellt, in welchem alle Theile unter einander ohne Unterbrechung zusammenhängen. Es ist ein Syncythium, dessen einzelne Zellen die verschiedenartigste Ausbildung erfahren haben. Seit fast zwei Decennien hat sich aher uber den elementaren Bau des Nervensystems bei vielen Forschern die sogenannte Neuronentheorie Eingang zu erringen gewusst; sie leugnet den stetigen Zusammenhang der Nervenzellen unter einander und ist also mit meinem "animalen Zellennetz" unvereinbar. I) Ergebnisse, welche eine neue von Camillo Golgi?) ausgearheitete Methode der mikroskopischen Techik zu

1) Obige Abhandlung ist der nach ten Gedüchtniss autgezeichnete, mit einigen Zusätzen verseliene. Inhalt moiner im Winter 1906 über die Neuronenlehre gchaltenen Vorlesungen. Ich ergreife das Wort an dieser stelle, weil der Weg strenger Beweistührung, dem ich bei dieser Frage seit vielen Decennien in meinen Vorlesungen gefolgt bin, noch keine Beachtung in der Literatur gefunden bat, und weil ich es für meine Pflicht halte, den durch jene Irrlehre hartnäckig fortwirkender Schädigungen der Wissenschaft auch meinerseits entgegen zu arbeiten.

2) Camillo Golgi, Untersuchungen üher den feineren Bau des centralen und peripherischen Nervensystems. (Aus dem Italienischen in's Deutsche iblersetzt ron Dr. R. Teuscher.) Jena 1894.

E. Pflüger, Archir für Physiolorje. Lit. 112 . 
Tage gefördert hat, führten zur Aufstellung dieser Neuronentheorie, von welcher A. van Gehuchten ${ }^{\mathbf{1}}$, etwas zu weit gehend, sogar behanptet, dass sie fast ein Decennium ohne Widerspruch geherrscht habe. Weil gewöhnlich die Golgi'sche Methode für die Neuronentheorie verantwortlich gemacht wird, muss sofort betont werden, dass Golgi selbst kein Anhänger dieser Theorie ist, die also nur der von gewissen Forschern gegebenen Deutung der mit Golgi's Methode erhaltenen Präparate ihren Ursprung verdankt.

Das Gewicht der mit Golgi's und anderen neuen Methoden der mikroskopisch - anatomischen Technik erlangten Ergebnisse wird aber dadurch sehr herabgesetzt, dass Forscher ersten Ranges, die sich seit vielen Jahren unausgesetzt mit dieser Frage beschäftigt haben, gerade in dem wesentlichen Punkte die entgegengesetztesten Ansichten vertreten.

Hierdurch ist der Beweis geliefert, dass die Technik der Untersuchung der Grösse der Aufgabe nicht gewachsen ist, so dass uns wesentliche Thatsachen zum Urtheile fehlen. Deshalb fragt es sich, $o b$ es nicht andere Wege der Erkenntniss gibt, wenn die mikroskopische Technik die ausreichende Aufklärung in diesem Falle versagt.

Solche Erkenntniss kann gewonnen werden durch Anerkennung der Wabrheit, dass die ganze lebendige Natur, um mit Plato zu reden, nur ein einziger Gedanke ist: unendlich viele Variationen auf denselben Grundplan. Begründung unwiderleglicher Kraft findet dieser Satz in der Abstammungslehre der lebendigen Organismen, welche erst der veroleichenden Anatomie den Stempel echter Wissenschaft aufgeprägt hat. Deshalb sehen wir die vollkommenste Uebereinstimmung in den Gesetzen, welche nicht bloss die Morphologie, das heisst die Entwicklung der Zellen und die Zeugung, sondern auch die chemische Metamorphose der lebendigen Substanz bei Pflanzen und Thieren beherrschen. Und ohne Zweifel gilt das auch für das vornehmste Gebilde, welches die Natur hervorgebracht hat, für das Nervensystem, dieses grösste Wunder der Welt, dem an geheimnissvoller Erbabenheit nichts vergleichbar ist. Auf den fest geordneten Bahnen der Nervenfasern eilen die Nervengeister, oder wie Helmholtz sagte, das Nervenprincip dahin, um Zellen oder Fasern zu beeinflussen. Wirkt nun das Nervenprincip hierbei so,

1) A. van Gehuchten; Bulletin de l'Acad. de Méd. de Belgique [4] t. 18 p. 30. 1904. 
dass die erregte Faser nur die Zelle oder eine andere Faser berührt? Oder verlangt die Uebertragung der Erregung, dass eine continuirliche organisirte Bahn vorhanden sei? Das ist heute die Losung im Kampfe: Continuität oder Contiguität. Für die Frage nach der Natur des Nervenprincipes ist die Entscheidung zwisehen beiden Möglichkeiten von der grössten Bedeutıng, wenn sie auch von einigen Seiten verkannt wird.

Einer der verdienstvollsten Anatomen aller Zeiten, Albert Köllike $\mathbf{r}^{1}$ ) beantwortete diese Frage am Ende seines Lebens, nach jahrelanger angestrengtester Erforschung des Baues des Nervensystemes in seiner letzten Arbeit (1915) dahin:

"Hauptorgane des Nervensystems sind die Neuronen "(Waldeyer), Neurodendren (ich) oder Neuren (Rauber). "Dieselben stellen anatomische Einheiten dar, von denen jede aus "einer Nerven- oder Ganglienzelle und einem Achsencylinder (Axon) „besteht, viele auch woch Protoplasmafortsätze oder Dendriten be"sitzen, welche beilen Theile ohne Betheiligung anderer Elemente "umuittelhar aus der Ganglienzelle hervorwahsen.

"Diese Neurouen sind nicht un in ibrer Ent"Wicklnng selbständige Bildungen, sondern erhalten "sich auch später als solche, verschmelzen wicht mit "einander und wirken nur durch Contact auf einander."

Wem eine Nervenfiser auf einc Zelle nur dadurch wirken soll, dass sie die Zelle berihrt, so unterliest die Unsicherbeit dieser Mechanik keinem Zweifel. Denn zwisehen Nerv und zelle, die vom Crewchssaft unspült simb, befindet sich immer eine capillare, die Oberflachen benetzende Flüssiglzeituschicht. Weil num Zellen je nach ihrem Eirnährungs- und Schwellungssrrad ihre Form und ihr Volum, und zwar oft sehr hedeutend, andern, würde immer die Gefahr vorhauden sein, dass der Contat versagt. -

Denkt mun ferner an die Millarden der feiusten Nervenfäserchen, welche im Gehirn und Rückenmark auf das Innigste sich verfechten, um den dichtesten Filz zu bilden, so müsste die Frregung, welche in einer Fibrille sich von der Peripherie unseres Körpers nach den Hemisphären des grossen Gehirus fortyflanzt, in Folge unendlich vieler Contacte mit anderen Fasern oder mit Zellen sich seitwärts ans-

1) A. Kölliker, Iic Entwickhng ler Elemente des Nervensystems. Zejtschr. f. wissensch. Zoologie Bd. \&2, sonilerablruck \$. 34. 1905. 
breiten; von einer isolirten und unverfälschten Leitung der Stärke und Qualität der Erregung könnte keine Rede sein. Wie wäre die scharfe Wahrnehmung aller einzelner Theile des Retinabildes begreiflich, wenn es keine isolirte Leitung des Nervenprincipes gäbe, an die wir älteren Physiologen immer geglaubt haben und glauben werden. -

Es ist ja wahr, der Räthsel sind viele in der lebendigen Natur; es ist aher die Frage, ob wir eine Nöthigung haben, uns Räthsel zu machen, wo keine sind - aus gar keinem anderen Grunde, als weil die anatomische Technik gewisse Structuren von unermesslicher Feinheit noch nicht darzustellen vermag. Die folgenden Betrachtungen sollen sich zunächst nur auf das Nervensystem der Wirbelthiere und des Menschen beziehen.

Voran muss ich die Wahrheit stellen, dass die Anhänger der Neuronentheorie sich durch denselben Grund widerlegen, den siegegen ihre Gegner als ausschlaggebend a ufstellen.

Der Denkfehler entwickelt sich sicher durch folgende Ueberlegung: Ein Naturforscher soll vor allem die Thatsachen achten und keine Gebilde annehmen, welche nicht nachgewiesen werden können. Ein Zusammenhang zweier centralen Ganglienzellen durch Anastomosen der Fortsätze dieser Zellen lässt sich auf keine Weise darstellen, darf also nicht angenommen werden. Da die centralen Ganglienzellen nun aber doch auf einander wirken, muss man die andere Annahme zulassen, dass die Zellen durch den Contact der von ihnen ausstrahlenden Fasern einander beeinflussen. Bei dieser Annahme liegt dem Anhänger der Neuronenlehre die Rechtfertigung in der Ueberzeugung, dass er ja einen Zusammenhang der Ganglienzellen unter einander auf das Allerentschiedenste ausschliesst. Gewiss! Er erreicht diesen Standpunkt aber nur durch die andere Ammahme des Contacts, ohne zu bedenken, dass diese Annahme niemals durch ein anatomisches Präparat begründet worden ist. Sie ist nur eine Folgerung aus der unberechtigten Abläugnung der Continuität. Wenn ein Anhänger der Neuronenlehre mir erwidern wollte, dass die centralen Ganglienzellen in einen Faserfilz eingebettet sind und desshalb von den Fasern sicher berührt werden, so weise ich darauf hin, dass dieser Faserfilz aus Neurogliafasern, aus Bindegewebefasern, aus Nervenfasern, aus faserigen Fibringerinnseln, aus Blutgefässen, aus Lymphgefässen und Gewebesaft besteht. $\mathrm{Ob}$ nun die Fasern, 
welche die Ganglienzellen berühren, Nervenfasern sind, ist keineswegs sicher. Gesetzt aber, es wäre nachgewiesen, dass Neurofibrillen die Oberfläche der Ganglienzellen oder Protoplasmafortsätze wirklich berühren, so könnte es sich doch um Neurofibrillen handeln, die aus derselben Ganglienzelle an einer anderen Stelle hervorgesprosst sind, wie etwa die Zweige einer Trauerweide den Stamm berühren, aus dem sie hervorwuchsen.

Die hier in das Auge gefasste Möglichkeit lässt sich leicht durch das anatomische Präparat begründen. Denn es ist bekannt, dass der Achseneylinderfortsatz einer centralen Ganolienzelle sich oft anf sehr weite Strecken verfolgen lïsst, während er fortwährend nach allen Seiten sich inmer wieder theilende Aeste abgibt, von denen einige bis in die nächste Nachbarsehaft ihrer Ganglienzelle zurückkehren. Ich weise zur Begründung hin auf Taf. 9 und 10 im Atlas von C. Golgi (Deutsche Ausgabe), wo Ganglienzellen aus dem Kleinhirn mit ihren Protoplasma- und Achsencylinderfortsätzen in schöner Weise dargestellt sind. Eine Ganglienzelle kann also umsponnen sein von Collateralen, dic ihr selbst angehören, die also Nichts beweisen dafür, dass eine Ganglienzelle ron Neurofibrillen einer anderen Ganglienzelle berühlt wird.

Eine zweite Thatsache muss berücksichtigt werden. Da die sensiblen Nerven beim Fintritt in die wraue Substanz sich anfspittern und zur Bildung des feinen Fasernetzes beitragen, also anch zur Umspinnung der Ganglienzellen, liegrt es auf der Hand, dass viele Neurofibrillen eine solche Ganglienzelle berühren könnten, die gar nicht von einer anderen Ganglienzelle herkommen.

Der Beweis kann also wur so geliefert werden, dass man unter dem Mikroskop die aus einer Ganglienzelle austretende Faser verfolgen kann bis zu dem Orte, wo sie die sicher einer zweiten Ganglienzelle zugehörige Faser berührt. Sind die heiden Ganglienzellen isolirt worden, weiss man nicht, ob eine etwa gefundene Berührung natürlich oder künstlich erzeugt ist. - Fis ist desshalb die Untersuchung an Schnitten nöthig. Da die Herstellung derselhen Frhärtung, also einen gewissen Grad von Schrumpfung der Gewebe voraussetzt, ist es ungewiss, ob nicht durch Contraction Contacte von Fasem erzielt wurden, die nur künstlich hergestellt sind. - Liesse sich nun in einem solchen Prïparate ein Contact zweier Fasern, die verschiedenen Ganglienzellen angehören, nachweisen, so qäbe es kein 
Mittel, zu entscheiden, ob da, wo Contact zu sein scheint, nicht doch Verwachsung vorhanden ist.

Ich glaube hiermit gezeigt zu haben, was sehr nothwendig war, dass die Theorie der functionellen Wechselbeziehung der centralen Ganglienzellen durch Contact eine jeder thatsächlichen Grundlage entbehrende Hypothese ist, für welche eben nur die nicht nachgewiesene Anastomose der Ganglienzellen in das Feld geführt wird.

Ich möchte aber doch die Histologen bitten, zu bedenken, wie oft sie widerlegt worden sind, weil sie leugneten, was sie nicht darstellen konnten.

Bald nach der Entdeckung der Ganglienzellen durch Ehrenberg ${ }^{1}$ ) unterscheidet G. Valentin als Urmasse des Nervensystems "Kugeln“, d. h. Ganglienzellen und die Primitivfasern. G. Valentin ${ }^{2}$ ) hebt hervor: "Beide gehen nirgends in "einander über, sondern befinden sich nur in dem "gegenwärtigen Verhältniss der Juxtaposition."

Wir wissen heute, dass diese Ansicht ein Irrthum war.

Mit welcher Bestimmtheit schrieb der berühmte Anatom $A l$ b e rt Kölliker in seiner grossen mikroskopischen Anatomie von 1850 Bd. 2 (1) S. 504 mit Bezug auf die Spinalganglien: „Die "Wurzelfasern treten beim Menschen und bei den ge"nannten Säugethieren in durchaus kein Verhältniss "Zu den Nervenzellen des Ganglion." Ferner (S. 508): "Ich bezweifle nicht im Geringsten, dass bei den „Fischen Ganglienkugeln, die zwei Nervenröhren den „Ursprung geben, sogenannte bipolare Kugeln, un"gemein häufig sind, - - allein ich leugnedas Vor„kommen ähnlicher Verhältnisse bei höberen Thieren "auf's Bestimmteste". Ferner hebt A. Kölliker nochmals hervor: "Ich finde und behaupte, dass bei Säugethieren „und beim Menschen keine einzige Nervenröhre der "sensiblen Wurzeln mit den Ganglienkugeln des "Spinalknotens in irgend welche Verbindung tritt, "vielmehr alle dieselben einfach durchsetzen."

Diese ganze Darstellung ist ebenso bestimmt als falsch. Das

1) Ehrenberg, Beobachtung einer auffallenden, bisher unerkannten Structur des Seelenorgans. Berlin 1836.

2) G. Valentin, Ueber den Verlauf und die letzten Enden der Nerven. Nov. acta Acad. Leopoldin. vol. 18. I. S. 159 (1836). 
hat "Kölliker ${ }^{1}$ ) auch später, nachdem er vielfach widerlegt war, zugegeben.

Zur Beachtung für die Histologen, welche mit so viel Entschiedenheit wie Kölliker bei den Spinalganglien mit negativen Beobachtungen die Neuronenlehre vertheidigen, erinnere ich noch an den Achsencylinderfortsatz der centralen Nervenzellen. Rud olf Wa $g$ ner ${ }^{2}$ ) ist der erste Forscher, welcher die zwei verschiedenen Arten von Fortsätzen der centralen Ganglienzelle erkannt hat: die Protoplasmafortsätze und den Achsencylinderfortsatz. Ich will die wichtigsten merkwürdigen Stellen hier angeben: "Von der Sub"stanz der Ganglienkörper selbst entspringen eine „grössere oder geringere Zahl Fortsätze, welche ganz „aus derselben körnigren Masse bestehen. - - Oefters "erscheinen diese Fortsäze ramificirt oder getheilt." Das sind also die Protoplasmafortsätze. Dann fährt er fort: „Oft "gelingt es wahrzunehmen, dass einer von den Fortsätzen ein "etwas anderes Ansehen hat als die anderen. Gibt es „auch Ganglienkörper, welche in dem Bau dieser Fortsätze in Bezug "auf Vertheilung, Länge und Anorduung, zrosse Verschiedenheiten "zeigen, so kommt doch ein grosser Theil darin überein, dass ein „Fortsatz - - sich durch besondere Länge und durch ,gleichmässigen Durchmesser von etwa $1 / 400$ Linie auszeichnet, und "den Charakter einer wirklichen Faser hat." - _. .Dieser Fortsatz ist "hlasser als dic anderen Fortsätze, weniger grauulirt, ziemlich gleich „breit, nie ramificirt oder an Ende verfeinert, und kann un das "Drei- und Vierfache der Länge des Ganglienkörpers verfolgt werden, „bis er ein queralgerissenes Fnde zeigt." Es kann bein Zweifel sein, Rudolf Wagner hat don Achsencylinderfortsatz richtig als besondere Art der Ganglienzellenfortsätze erkannt.

Rud olf Wagner's zunächst beim elektrischen Lappen des Torpedo gemachte Entreckung ward dann von R. Re m a k $\mathbf{k}^{3}$ ), hesonders aber von ()tto Deiters ${ }^{4}$ ) als ein allgemeines Gesetz für alle centralen Ganglien-

1) A. Kölliker, Handb. d. Gewebelehre, 6. Aufl., Bd. 2 Hälfte 1 S.41. 1898.

2) Rudolf Wagner, Sympathischer Nerv, Ganglienstructur und Nervenendigungen in Wagner's Wörterhnch der Physiol. Bal. 3 Abth. 1 \$. 377. 1846.

3) R. Remak, Dentsche Klinik 1855 s. 295.

4) Otto Deiters, Untersuchungen über Gehirn und Rückenmark. Nach den Tole des Verfassers herausgegeben und bevorwortet von Max Schultze. S. 57 und Vorrede S. XIIl. Braunschweig 1865. 
zellen bestätigt, vor Allem, dass der Achsencylinderfortsatz sich niemals theilt oder Aeste abgibt. Deiters entdeckte den Uebergang des Achsencylinderfortsatzes in die markhaltige Primitivfaser. Max Schultze und alle anderen Histologen bestätigten den ungetheilten Verlauf des Achsencylinderfortsatzes. Wemm man hört, dass die ersten Autoritäten vor C. Golgi einstimmig den Achsencylinderfortsatz als eine auf weite strecken verfolgbare, scharfbegrenzte Faser bezeichneten, welche niemals Aeste abgibt; dass dann C. Golgi den Achsencylinderfortsatz als eine Faser darstellte, welche immer Aeste abgibt, die sich wieder verzweigen, um so eine Baumkrone von oft ausserordentlicher Ausdehnung zu erzeugen, dann möchte man Dies nicht für möglich halten, wenn es nicht so verzweifelt wahr wäre. Wenn aber die Golgi'sclie Methode sich zur Darstellung gewisser Structurverhältnisse als vorzüglich bewährt hat, folgt daraus doch nicht, dass sie absolut vollkommen sei. A pathy hat ja besonders gezeigt, dass es Structurverhältnisse im Nervensysteme gibt, die sie nicht zù enthüllen vermag.

Nicht auf den Boden der Hypothese will ich mich stellen, sondern nach Thatsachen suchen, welche von Autoritäten ersten Ranges festbegründet sind, und bezeugen, wie die anatomische Beziehung eines Nerven beschaffen ist, der auf eine Zelle wirkt oder von ihr beeinflusst wird.

Gar Mancher wird geneigt sein, mich zu tadeln, wenn ich demgemäss „bekannte Thatsachen" in breiter Darstellung hier vortrage. Aber diese Thatsachen sind die Bausteine für mein Gebäude, und aus denselben Bausteinen kann man sehr verschiedene Häuser aufführen. Nicht alle Bausteine kann ich verwenden, obne dass ich sie behaue, d. h. ihren wahren Werth durch kritische Zergliederung erkämpfe. Deshalb ist der von mir einzuschlagende Weg gerechtfertigt.

Hierbei werde ich das gesammte Thierreich berücksichtigen und nicht bloss die Wirbelthiere.

Dieser Satz, welcher mir selbstverständlich scheint, erfreut sich leider keiner allgemeinen Anerkennung. Denn kein Geringerer als Albert Kölliker ${ }^{1}$ ) schliesst seine letzte grössere Arbeit über die Entwicklung der Elemente des Nervensystems mit den Worten:

1) A. Kölliker, Die Entwicklung der Elemente des Nervensystems. Zeitschr. f. wissensch. Zoologie Bd. 82 S. 36, Sonderabdruck. 1905. 
"Zum Schluss noch die Bemerkung, dass meine Auseinander"setzung sich nur auf die Wirbelthiere bezieht und die Wirbellosen „gänzlich ausser Augen lässt.

„Meiner Ansicht zufolge ist kein Grund vorhanden für die "Annahme, dass der feinere Bau des Nervensystems bei allen Ge"schöpfen derselbe sei, und werden noch zahlreiche Untersuchungen "nöthig sein, um über die allmähliche Entwicklung dieses Systems "Klarheit zu gewiunen."

Wie der hochverdiente Altmeister zu obigem Standpunkte gelangen konnte, wird mir einigermaassen verständlich, wenn ich an die ansgedehnten Untersuchungen denke, welche er auf alle Theile des Nervensystems und ihre Entwicklung bei sehr vielen Thierklassen ausdehute. Bei den grossen Modifikationen, welche die einzelnen Bildungen erleiden, wird es dem gewissenhaften Forseher gewiss oft schwer orjer gar unmöglich, den ruhenden Pol in der Erscheinungen Flucht zu finden. Je zahlreicher die Fälle sich häufen, wo diese Schwierigkeiten auftreten, un so mehr wird die Ueberzeugung erschüttert, dass in deu grnssen Modifikationen doch derselbo Plan vorliegt.

Das grossartige System der vergleichenden Anatomie der Pflanzen und Thiere kamn aber heute keinen Zweifel lassen, dass es sich aberall in der Natur um das Leben der Zellsubstanz handelt, deren Grundeigensehaften immer dieselben sind, wem es anch oft genum nicht mönlich ist zu zeigen, wie die hesoudere Form ans dem Urplan aboleitet werden muss.

Trotzdem will ich liich strenger an die wirklichen Thatsachen halten, als die Anhänger der Neuronenlehre es thun. Unsere Aufgabe ist also zu entscheiden: ob die Leitung von einer Nervenfaser auf eineZelle oder von der Zelle aufdie Nervenfaser durch Contact oder Continuität sich vollaieht.

Wenn ich das Augenmerk zuerst auf die cerebrale Ganglienzelle eines centrifugalen Nerven (siebe unsere Fig. 1) und ihre Beziehung zu dem aus ihr hervortretenden Achsencylinder wende, sei zur Erklärung Folgendes bemerkt. Das I'räparat entstammt einer Arbeit von Max Schultze ${ }^{1}$ ). Es ist eine Nervenzelle aus dem

1) Maximilianus sihult\%e, Observationes de structura cellularum tibrarumque nervearum. Bonnate, anro MnCCELXIX. 
Lobus electricus im Gehirn von Torpedo marmorata, $350 \mathrm{mal}$ vergrössert. In unserer Nachbildung ist das Original ungefäbr auf die

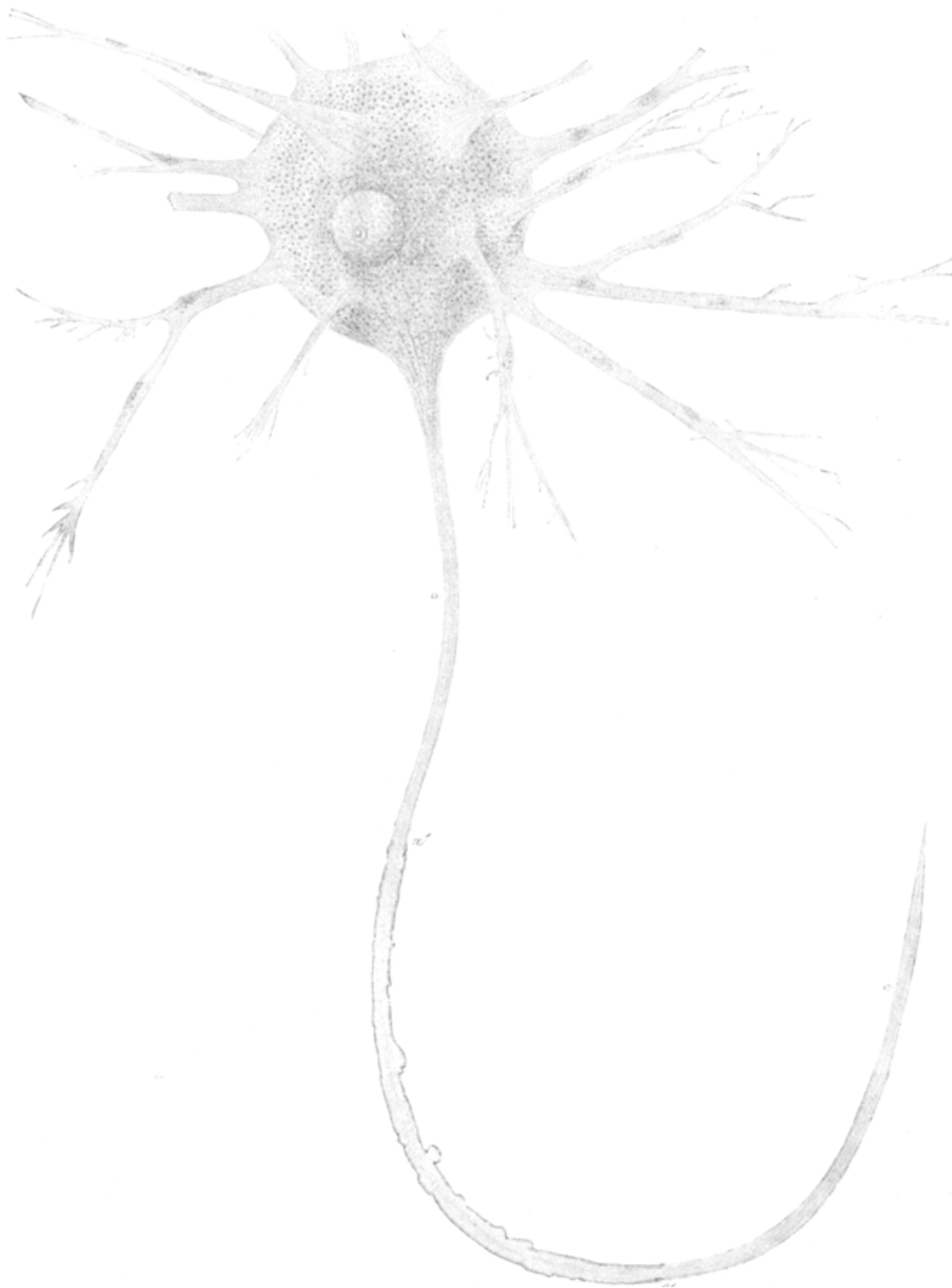

Fig. 1.

Hälfte verkleinert. Viele Fortsätze, welche verästelt sind, ausser einem, dem sogenannten Achsencylinderfortsatz (a), an dem bei $\left(a^{\prime}-a^{\prime}\right)$ 
die Markscheide wahrzunehmen ist. Alle Fortsätze zeigen in ausgezeichneter Weise fibrilläre Structur. Die Isolation wurde durch 24 stündjge Behandlung mit Jodserum erreicht. Es kann nicht bestritten werden und wird in diesem Falle auch von den Anhängern der Neuronenlehre nicht bestritten, dass Continuität vorliegt. Die Neurofibrillen der Zelle gehen direct in den Achsencylinder der markhaltigen Nervenfaser über. Nach der Neuronenlehre wird aber die Ganglienzelle der centrifugalen, z. B. des motorisehen Nerven vom Gehirn aus dadurch erregt, dass feine Fibrillen ihre Oberfläche oder ihre Protoplasmafortsätze durch Contact beeinflussen. Demgemäss würde die cellulifugale Leitung durch Continuitä, die cellulipetale aber durch Contact vermittelt. I)as widerspricht unserem Glauken an die ausnahmslose Geltung der Grundgesetze. Sicher ist in diesem Falle unserer Fig. 1 nur die Continuität. Abcr wut! Sollte der schon von A. van (xehuehten ${ }^{1}$ ) besonders betonte Umstand etwa in Betracht kommen, dass die narh der Ganglienzelle serichtete Innervation (die cellulipetale) etwas Anderes als die collulifugale wäre. [)as wirl sofort dureh das spinaleangliou widerlegt, wie heistebende Fig. 2 nach Kölliker ${ }^{2}$ ) bezengt. Es siud ,bipolare Ganglienzellen aus einem Ganglion sacrale

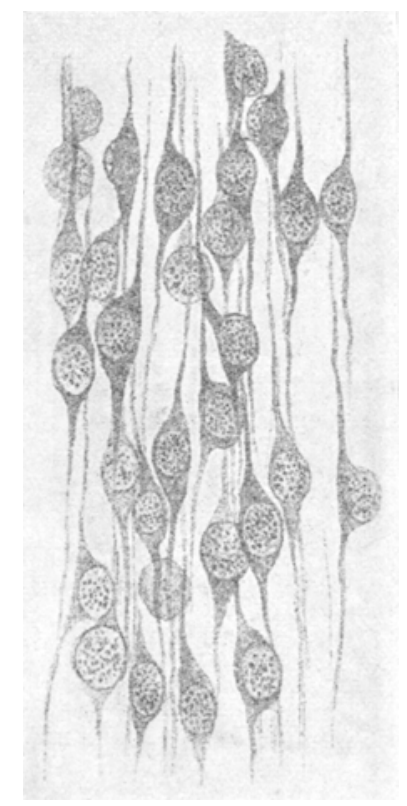

Hig. ؛. eines Embryo des Menschen vom Ende des zweiten Monats". Es besteht für die zuführende und abführende Nervenfaser unzweifelhafte Contiruität. Rudolf $\mathrm{Wagner}^{3}$ ) ist der Entdecker der Thatsache, „dass

1) A. va n Ge h u chten, Bull. de M'Acad. de Mél. de Belgique [4| t. IE p. 29.1904.

2) Albert Kölliker, Die Lintwicklung der Elemente des Nervensystems. Zeitschr. f. wissensch. Zoologie Bd. 82 S. 3, Sonderahdruck. 1905.

3) Rudolf Wagner, Mittheilung an die Kgl. Societat der Wissenschaften in Göttingen unter dem 31. December 1846. Citirt aus Rudolf Wagner's Artikel: Sympathischer Nerv, Ganglienstructur und Nervenendigungen. Siehe Wag ner's Wörterbuch der Physiologie Ba. 2 Abth. 1 S. 3961. 
„an eine jede Spinalganglienzelle vom Centraltheil aus eine Primitiv„faser tritt, und dass ebenso am entgegengesetzten Pol der Ganglien"zelle eine Fibrille nach der Peripherie abgeht."

Ganz dasselbe wird bezeugt durch die von Max Schultze ${ }^{1}$ ) beschriebenen merkwürdigen bipolaren Ganglienzellen (siehe unsere Fig. $3 \mathrm{~A}$ und $3 \mathrm{~B}$ ).

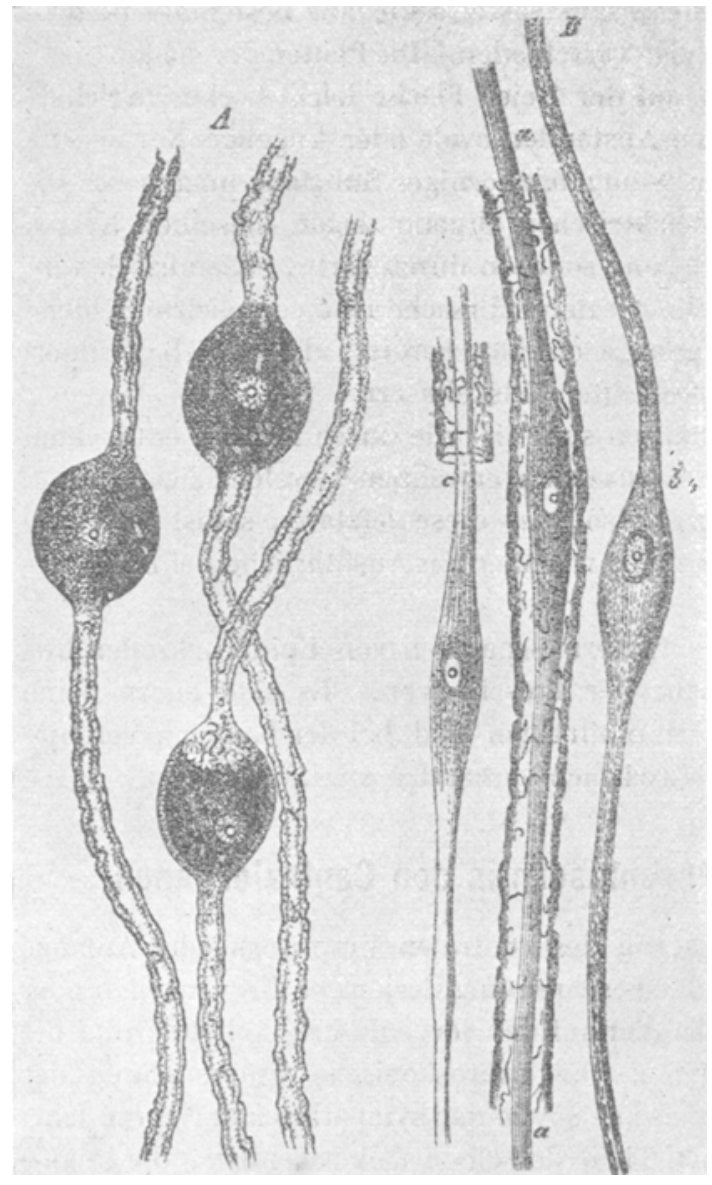

Fig. 3.

Dass die Fortsätze Nervenfasern sind, „tritt", wie Max Schultze sagt, „bei gewissen bipolaren Ganglienzellen am deutlichsten ent-

1) Max Schultze, Allgemeines über die Structurelemente des Nervensystems. Siehe Stricker's.Handbuch der Lehre von den Geweben Bd. 1 S. 126. 1871. 
„gegen, welche sich in den Verlauf markhaltiger Nervenfasern „einbetten, wie sie z. B. leicht schon im frischen Zustande aus den "Spinalganglien von Rochen und Haifischen isolirt werden liönnen, "wie Robin und Rudolf Wagner sie zuerst 1847 kennen lehrten, "oder aus dem Ganglion Gasseri derselben Thiere, wie ich sie "mit grosser Leichtigkeit darzustellen vermochte, oder aus demselben "Ganglion der Knochenfisehe (Hecht nach Bidder) oder aus dem "Nervus acusticus vor seinem Eintritt in die Labyrinthsäckchen. "Die Zellsubstanzist hiereine Fortsetzung der Achsen"cylindersubstanz; sie umschliesst Kern und Kern"körperchen; die Markscheide hört gewöhnlich an dem Ursprung „der Fasern in die kernhaltige Verdickung des Achsencylinders auf und „stellt sich gegenüber an der entsprechenden Stelle wieder ein; "seltener reicht sie über die, ganze Zelle hinüber, sie eimhüllend, so "dass die verdickte Stelle keine Unterhreehung in der Markscheide "veranlasst. Eine solche Ganglienzelle ist demgemäss eine kern"haltige Stelle des Axencylinders. Die fibrilläre Structur des "letzteren lässt sich a ch in die Zellsubstanz verfolgen, "wird jedoch dureh ansehnlichere Mengen feinkörniger interfibrillärer ,Substanz theilweise verdeckt. Wie die Markscheide zum Begriff "der Nervenfaser nicht notbwendig gehört, so stellt sie auch an der "Ganglienzelle nur eine accessorische Hulle dar, die sogar nur in „selteuen Fällen vollständig jst. Die Schwann'sche Scheide "setzt sich, wenn sie vorhanden ist, continuirlich auch über die "Ganglienzelle fort und bildet die oben erwähnte kernhaltige lindengewehige Hülle derselben. An den bipolaren Ganglienzellen des "Acusticus fehlt sie." Die Fig. 3 gibt einige Beispiele: A Drei bipolare Ganglienzellen aus dem Ganglion Gasseri vom Heeht, nach Bidder. $B$ Drei bipolare Ganglienzellen aus dem N. acusticus vom Hecht; ", noch in ler Markscheide; b, sanz; c, theilweise entblösst, um zu zeigen, dass die Ganglienzellen nur kernhaltige Anschwellungen des Achsencylinders sind, nach Max Schultze. Diese von Max Schultze dargelegten Thatsachen bezeugen in sicherer Art, dass in zahlreichen Fällen sowohl die zur Ganglienzelle führende wie die ableitende Faser mit derselhen in continuirlichem Zusammenhange steht.

Es soll nunmehr meine Aufqabe sein, zu untersuchen, in welcher anatomischen Beziehung eine centrifugale Nervenfaser zu dem Endapparat steht, auf den sie wirkt. 


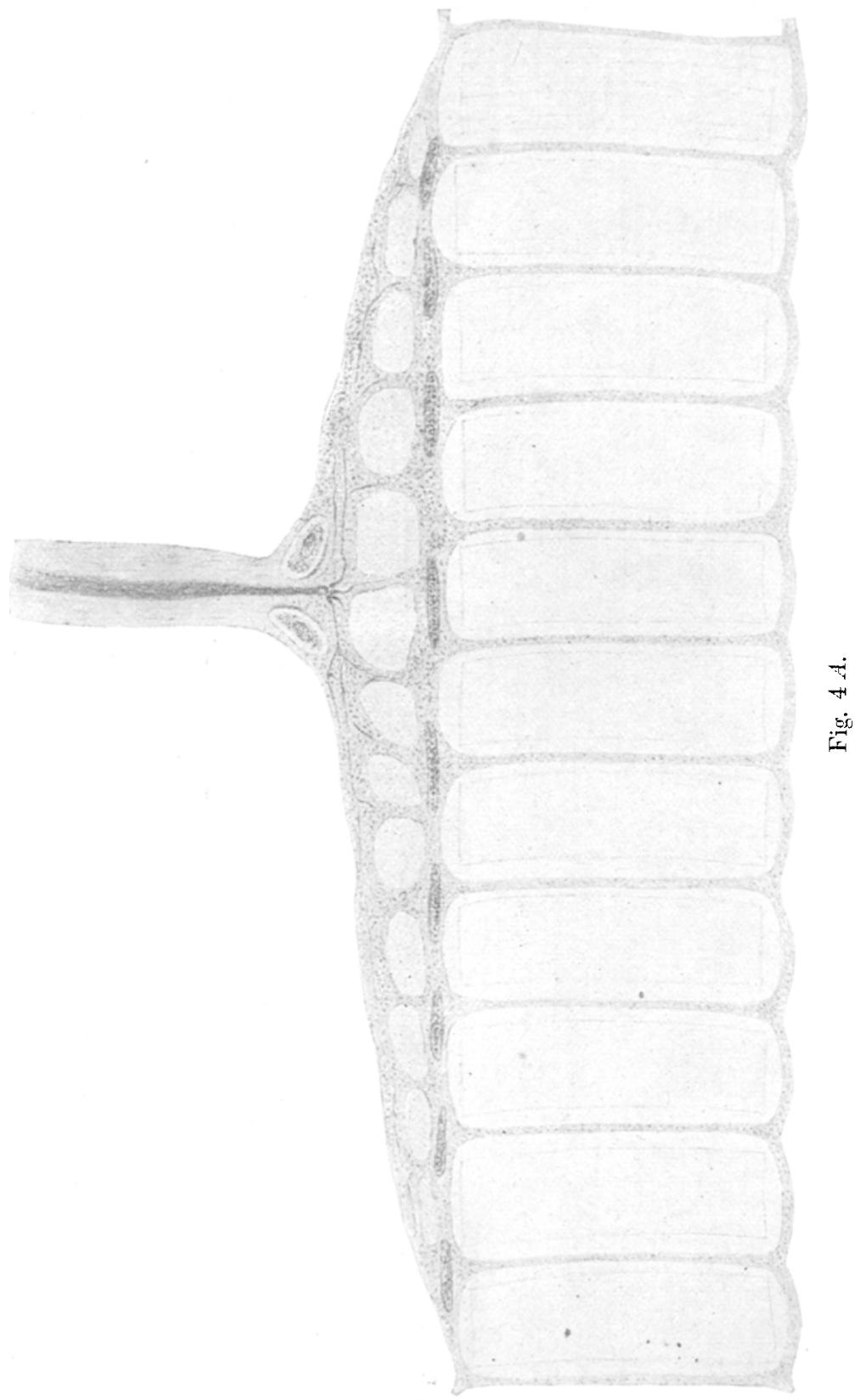

Indem ich mit den motorischen Nerven begizne, benutze ich als erstes Beispiel die Muskelfasern der Insekten Hydrophilus piceus, 
Aphodius rufipes und Musca vomitoria nach von A. Rollett ${ }^{1}$ ) mitgetheilten Präparaten.

Wie man an denselben sieht (siehe Fig. $4 A$ u. $4 B$ ), ist der quergestreiften Muskelfaser der von Doy è $\mathrm{e}^{2}$ ) entdeckte Nerven-

lü̈gel aufgelagert, welcher aus Protoplasma hesteht, in das Zellkerno eingebettet sind. Weil das Sarkolemm Muskelfaser und Nervenhügel

1) Alexander Rollett, Intersuchningen übur den Bau der quergestreitten Muskelfasem. Theil I. Kaiscriche Akad. der Wissensch. I31. 49 Taf. II Fig. 9 u. Fig. 10. 1885.

2) I) y ỳre, Mémoire sur les Tardigrades. Annal. des sciences nat. 2. serie. T. 14 p. 316. 1840. Pl. 17 Fig. $1-4$. 
umschliesst, stellt die umschlossene Masse ein Syncythium vor, wobei die Zellsubstanz sowohl wie die Kerne sehr verschiedenartige Differentiationen erfahren haben. Mit absoluter Sicherheit ist hier zu sehen, dass der Nerv das Sarkolemm durchbohrt und sich dann in viele feine Aeste spaltet, welche in das Protoplasma des Nervenhügels eindringen und beim weiteren Verlauf sich verlieren. Worauf es bei diesem hochwichtigen Präparate ankommt, besteht darin, dass die Fibrillen des Achsencylinders gerade so in das Protoplasma des Syncythiums der Muskelfaser ausstrahlen wie der Achsencylinder in die motorische Ganglienzelle. Das ist auch die sicher richtige Auffassung von A. Rollett. Denn er sagt:

„Das Sarkoplasma geht ohne Unterbrechung über in die nerven"tragende Substanz der Nervenhügel der zu den Muskelfasern zu"tretenden motorischen Nerven" (a. a. O. S. 3).

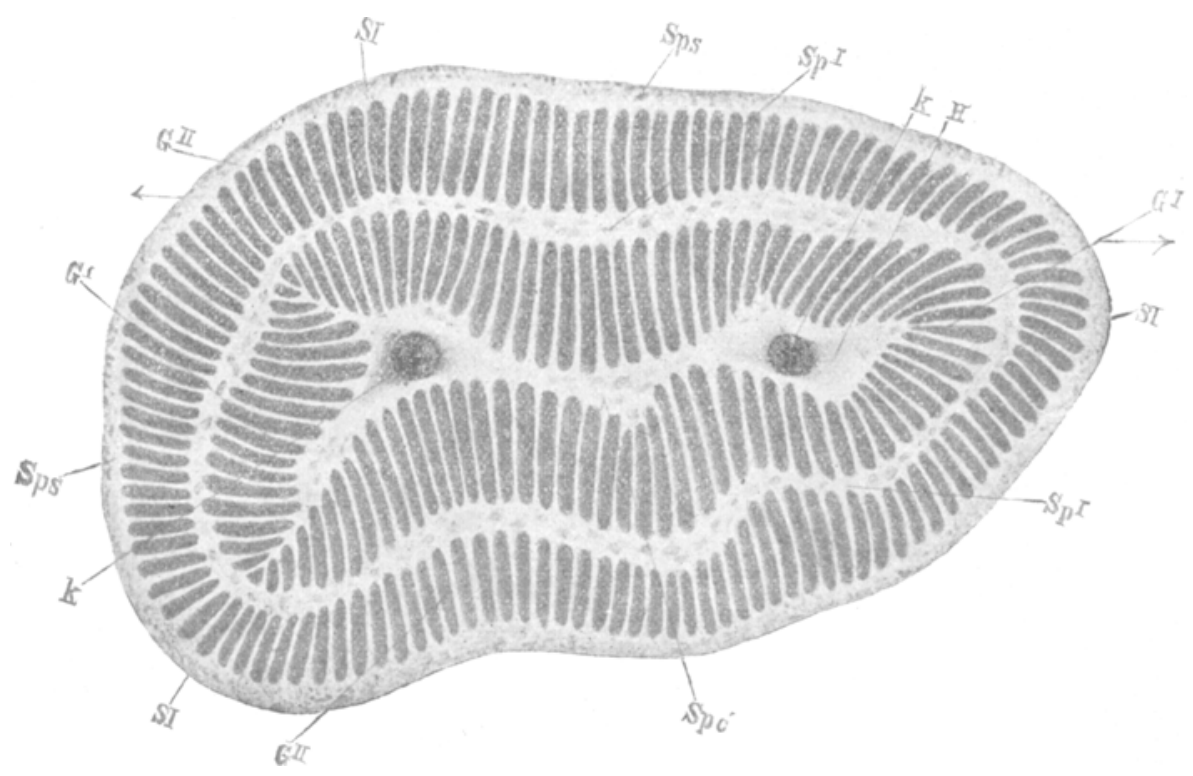

Fig. 5.

In der That zeigen besonders schön Querschnitte der Muskelfasern von Insekten, wie sie A. Rollett ${ }^{1}$ ) auf Fig. $11 A$ Taf. II von Musca vomitoria dargestellt hat (siehe unsere Fig. 5), dass das un-

1) Alexander Rollett, Unsersuchungen über den Ban der quergestreiften Muskelfasern. II. Theil. Kaiserl. Akad. d. Wissensch. Bd. 51. 
mittelbar unter dem Sarkolemm angebäufte Sarkoplasma sich durch zwischen den Fibrillenbündeln klaffende Spalten stetig in das interfibrilläre Sarkoplasma fortsetzt. Zum Verständniss der Figur 5: $k k$ sind Kerne, $H$ Sarkoplasmahof um $k k, S p c$ centrales Sarkoplasma, $G_{I} G_{I I}$ die Cohnheim'schen Felder, $S p^{l}$ Sarkoplasma zwischen den beiden Gürteln der Cohnheim'schen Felder, Sps äusserste Lage von Sarkoplasma unmittelbar unter dem Sarkolemm.

Rollett ${ }^{\mathbf{l}}$ ) beschreibt nun die Endigung des Nerven in folgender classischen Weise:

„Am weitesten konnte ich den zutretenden Nerven in die "Sulbstanz des Nervenhügels an Tinctionspräparaten, die zuerst "mit Carmin und dann mit Hämatoxylin gefärbt wurden, verfolgen. "An diesen sah ich Bilder wie Fig. ( "zutretende Nerv breitet sich in der äusseren Partie des Nerven„hügels sich dichotomisch theilend aus. Die feinen Zweige begaben , sich in die Tiefe, waren aber bald, in der Substauz des Hügels „sich verlierend, nicht weiter zu verfolgen. Bilder von der Nerven"ausbreitung im Hügel bei Hydrophilus, die dem in Fin. 9 dar"gestellten glichen, erhielt ich sehr regelmässig, wenn ich lebende "Kaffer nach Entfernung des Abromens in die Kleinenherg'sche "Pikrinschwefelsiure brachte und darnach, so wie das Kleinen"herg für seine Präparate angibt, anfangs in schwächeren und "daun in stärkeren Alkohol and die von diesen Käfern erhaltenen "Muskelfasern zuerst mit Carmin und darauf mit Hämatoxylin fürbte."

Diese Beobachtungen von $A l$ exander Rollett üler die Endigung der Nerven in den quergestreiften Muskeln sind die wichtigsten der gesammten Literatur. Denu sie beweisen, dass

1. der motorische Nerv das Sarkolemm durchbohrt; und dass

2. der Achsencylinder in das Protoplasma des Nervenhügels eindringt und in feine Fasern sich theilend und ausstrahlend der weiteren Beobachtung sich entzieht.

Iliermit ist hewiesen, dass die Nervenendigung intracellular ist, sowie dass der Nervenhügel selbst nicht als Nervenendigung angeseben werden kann.

1) Alexander Rollett, Untersuchungen über den Bau der quergestreiften Mnskelfasern. Kaiserl. Akad. d. Wissensch. zu Wien Bd. 49, Sonderabilr. S. 30. 1885. 
Indem ich zu den Wirbelthieren übergehe, wähle ich zuerst die anatomische Beziehung des motorischen Nerven zu der quergestreiften Muskelfaser der Batrachier und stütze mich dabei wesentlich auf die Forschungen von Wilhelm Kühne (1859), M. Rouget (1862), Th. Wilhelm Engelmann (1863) und Stephan Apathy (1899).

Die beifolgende Fig. 6 bezeugt für den Frosch nach W. Kühne ${ }^{1}$ ), dass der markhaltige Nerv $(\mathrm{mm})$ das Sarkolemma (s) durchbohrt. Denn das Neurilemm ( $n$ ) geht stetig in das Sarkolemm (s) über. An der Durchbohrungsstelle hört das Mark auf; der Nerv setzt sich aher in mehrfach sich theilende blasse Fäden $(A)$ im Inneren der Muskelfaser fort und wird von kernartigen Gebilden $(E)$ begleitet, welche von den Kernen der eigentlichen Muskelsubstanz verschieden sind.

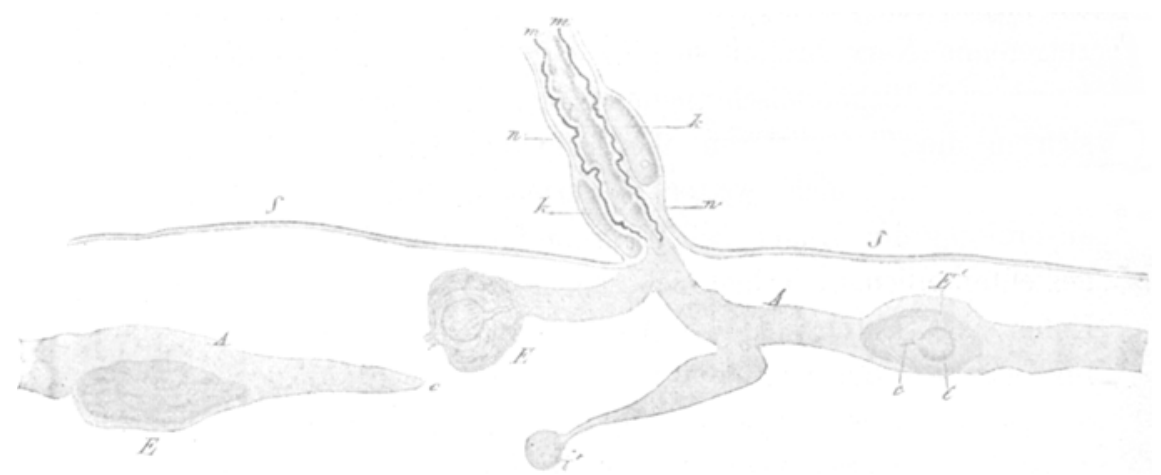

Fig. 6.

Th. Wilhelm Engelmann ${ }^{2}$ ) hat die anatomischen Beziehungen des Nerven zu der Muskelfaser bei Rana esculenta in einer ausgezeichneten, von wahrhaft physiologischem Geiste durchdrungenen Abhandlung durch vielfache Abbildungen erläutert. Ich betrachte zunächst seine Fig. 4 Taf. II, welche ich hier wiedergebe (als Fig. 7). Leider fehlt bei Engelmann eine Angabe über die Bedeutung der Buchstaben bei den Figuren. Doch wird jeder Sachverständige sich das leicht ergänzen. Das Präparat bestätigt im Wesentlichen die Angaben Kühne's und lehrt, dass eine markhaltige Faser sich in mehrere kurze Aeste spalten kann, die dann, das Sarkolemm durchbohrend,

1) Dr. W. Kühne, Ueber die peripherischen Endorgane der motorischen Nerven. Leipzig 1862. Fig. 18 Taf. V.

2) Th. Wilhelm Engelmann, Untersuchungen über den Zusammenhang von Nerv und Muskelfaser. Leipzig 1863. 
Ueber den elementaren Bau des Nervensystems.

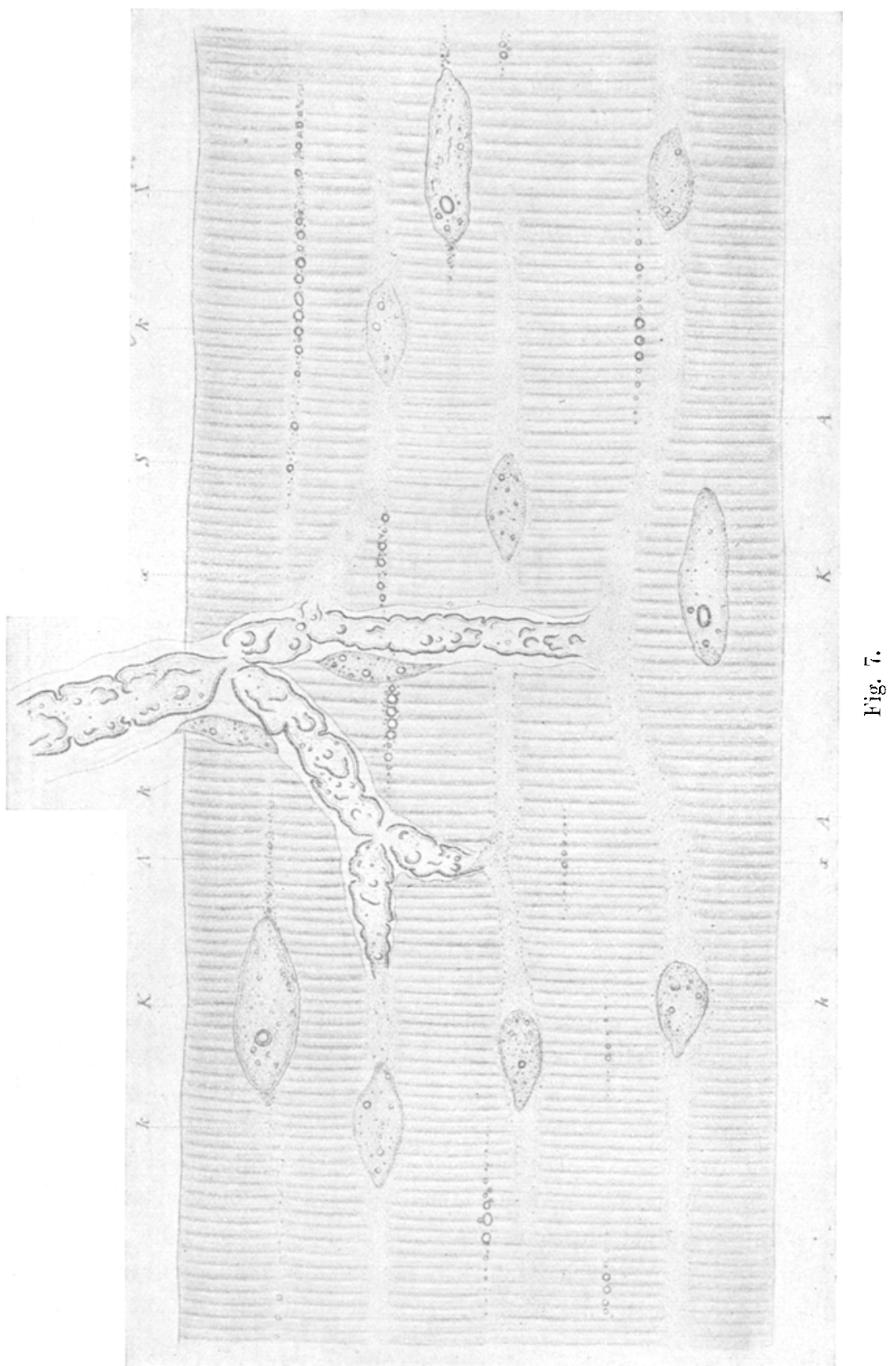


in das Innere der Muskelfaser eindringen. Engelmann's Auffassung der Verhältnisse ist von so hervorragender Bedeutung, dass ich es für nothwendig halte, dieselbe wörtlich nochmals der gegenwärtigen Zeit zur Beachtung mitzutheilen ${ }^{1}$ ).

„Nach genauer Untersuchung einer Anzahl meiner Profilbilder bin "ich zu der Ueberzeugung gekommen, dass die blassen Endfasern aller"dings unter das Sarkolemm treten und zwischen diesem und der quer"gestreiften Substanz hinziehen. Ich habe mich aber ebenso bestimmt "auch davon überzeugt, dass (namentlich bei Bombinator) die blassen "Endfasern häufig erst eine Strecke weit ausserhalb des Sarkolemms „verlaufen, ehe sie dasselbe durchbohren. - - - Bei Profil"ansichten (Fig. V in Engelmann's Abhandlung) sieht man nun „Folgendes. Dals Sarkolemm erscheint als eine scharfe doppelt con"tourirte Linie, welche an der Stelle, wo der bis dahin meist noch "dunkelcontourirte Nervenendzweig hindurchtritt, eine Unterbrechung "zeigt. Betrachtet man den Nerv genau, so sieht man, dass sein "Neurileinm mit dem Sarkolemm verschmilzt, das Mark verschwindet "und er sich in Form einer zarten blassen Faser fortsetzt, welche "der quergestreiften Substanz unmittelbar aufliegt, zuweilen in die"selbe eingebettet erscheint. Das Sarkolemm zieht über der blassen "Faser hinweg und ist an den Stellen, wo in der letzteren ein Kern „liegt, nach aussen hervorgewölbt. Nach dem Ende zu verlieren "die Umrisse der intramuskulären blassen Faser an Deutlichkeit, sie „gleicht einer äusserst feinkörnigen Masse, welche sich in der quer„gestreiften Substanz verliert". - _ - Ferner: „Für ein directes "Uebergehen der blassen intramuskulären Faser in die quergestreifte "Substanz liefert auch folgende, häufig von mir beobachtete Er"scheinung einen Beweis. Behandelt man eine Muskelfaser vom "Frosch, die ein gutes Bild der Nervenendausbreitung zeigt, mit "Chlorwasserstoffsäure von 1 pro mille, so wird bekanntlich das "Syntonin gelöst, der Nerv aber unversehrt erhalten. Es gelingt "nun nicht schwer, den ganzen Muskelinhalt zun Ausfliessen zu „bringen, wenn das Sarkolemm an irgend einer Stelle zerrissen ist. "Betrachtet man, nachdem der Inhalt des Sarkolemmschlauches mit "den Muskelkernen ausgeflossen ist, eine blasse Endfaser, so sieht „man, dass sie ganz continuirlich übergeht in eine breitere, helle, „feinkörnige Masse, die häufig noch Spuren der Querstreifung zeigt

1) Th. Wilhelm Engelman, a. a. O. S. 19. 
"und weiter nichts ist als ein Rest der contractilen Muskelsubstanz, "welcher mit der Nervenfaser auf das Innigste verschmolzen ist. "(Fig. III bei Engel„mann, hier Fig. 8.)

"Zuweilen haftet an "diesen Resten von Muskel"substanz noch ein Muskel"kern. und man kann dann "mit Hülfe der Schraube „ganz deutlich verfolgen, "dass die den Muskelkern „umgebende Substanz un"unterbrochen in die "Nervenendfaser über,geht. Die zunächst mit "den Nerven zusammen„hängende Muskelsubstanz ", wird jedenfalls in ihrem "chemischen Verhalten "sich der blassen Faser, .d. h. dem Achsencylinder, "nähern und in Folge "dessen von der ange"wandten Süure nicht in "dem Maasse angegriffen "werden, wie die übrige, "von der blasseu Faser „entfernter liegende, nicht "so unmittelbar mit der„selben zusammenhän"gende Muskelmasse. Fs "wird also auch "ypder "chemischen Zusammen. "setzung nach ein ganz "continuirlicher Ueber"gang zwischen Achsen„cylinder und contractiler Muskelsubstanz stattfinden. - Die blassen „Fudfasern müssen wir, Kühne's Beispiel folgend, für Fort„setzungen des Achsencylinders ansehen, da weder Neurilemm noch 
"Markscheide sich mit unter das Sarkolemm begeben; mit $\mathrm{Kühne}$ "können wir sie also von ihrem Eintritt in die Muskelfaser an intra"muskuläre Achsencylinder nennen."

Diese Beobachtungen und Auffassungen sind von unschätzbarem Werthe. Nur in einem Punkte möchte ich eine Modification der Deutung der blassen intramuskulären Nervenfasern des Frosches vorschlagen.

Wie man sieht, scheint beim Frosche der Nervenhügel zu fehlen, der doch im Thierreich so allgemein verbreitet bei Wirbel'osen und Wirbelthieren auftritt. Wir haben gesehen, dass bei Hydrophilus und Aphodius die Verästelungen der intramuskulären Achsencylinder umhüllt werden von einer feinkörnigen kernetragenden Substanz. Da nun Achsencylinder kernlose Gebilde sind, so müssen die Zellkerne, welche die blassen intramuskulären Nervenfasern des Frosches begleiten, als Anlagerungen auf die Achsencylinder betrachtet werden, welche noch eine feinkörnige Substanz begleitet. Demgemäss ist auch beim Frosch eine dem Nervenhügel entsprechende Umscheidung der Achsencylinder vorhanden, welche nur eine in Strahlen zerklüftete Differentiation erfuhr. Ob diese protoplasmaartige Hügelsubstanz die Bedeutung hat, die Erregung vom Achsencylinder auf die contractile Substanz zu übertragen, bleibt vor der Hand unbekannt. Das ist aber für die Frage, welche uns hier beschäftigt, nicht von Bedeutung.

Wir wenden uns jetzt zu der von Doyère bei Wirbellosen und von $\mathrm{Rouget}{ }^{1}$ ) bei Wirbelthieren entdeckten verbreiteten Form der Endigung des motorischen Nerven in der Muskelfaser. Als Beispiel wähle ich aus Engelmann's Arbeit ${ }^{2}$ ) dessen Fig. XIV auf seiner Tafel IV und gebe sie hier wieder als Fig. 9. Sie stellt den Nervenhöcker „aus einem noch zuckenden Psoas von Lepus Cuniculus" vor. Wie man sieht, setzt sich der Nerv unmittelbar in den Nervenhügel fort. Das kernhaltige Neurilemm geht ununterbrochen in das Sarkolemm über. Das Nervenmark hört da auf, wo der Nerv das Sarkolemm durchbohrt. Engelmann betrachtet nun den Nervenhügel als verbreitertes Ende der Nervenfaser, das er „End-

1) Rouget, Note sur la terminaison des nerfs moteurs dans les muscles chez les reptiles, les oiseaux et les mammifères. Compt. rend. t. 55 p. 548 . 29. Sept. 1862.

2) Th. W. Engelmann, a. a. O. S. 23. 


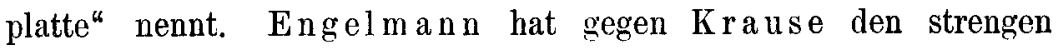
Beweis geliefert, dass die Endplattè unter und nieht auf dem Sarkolemm liegt, wie es bereits von $\mathrm{Rouget}^{1}$ ) richtig erkannt worden war. Endplatte und contractile Substanz berühren sich direct, sind nicht durch eine Membran von einander geschieden. Untersucht man „nach Behandlung mit verdünnter Essig- oder Chlorwasserstoff„säure, so sieht man mit unzweideutiger Klarheit, dass das Sarko"lemm, sobald es an die Peripherie der Endplatte gelangt ist, sich "an die vom Muskel abgewandte Seite der Platte anlegt und die

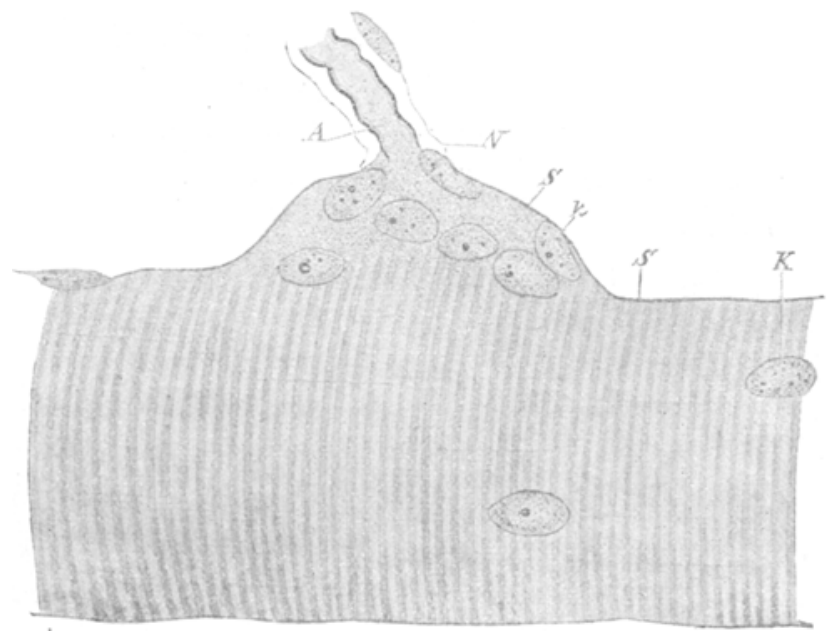

Ijg. $y$.

„ganze Platte üherzieht." Um zu beweisen, dass dif Endplatte nicht etwa durch eine Membran von der contractilen Substanz getrennt, also zwischen zwei Membranen eingeschlossen liegt, behandelte Engelmann mit Chlorwasserstoffsäure von 1 pro mille wahrend etwa vier Tagen. Die Endplatte hat sich an ihrer sanzen Peripherie abgerundet und scharf von der üherkleilenden Membran und dem Inhalt der Muskelfaser abgehohen. „Nirgends lässt sich eine unterhalb der Platte linziehende Membran erkennen." - Lässt man jetzt Kalilauque zu dem Präparate treten, verschwinden Endplatte, Kerne und Muskelinhalt und nur das Sarkolemm bleibt erhalten, das sich, "wie man nun nit überraschender Klarheit sieht, über die „nunmehr fast unkenntliche Endplatte hinwegwölbt. Man sieht, dass.

1) M. Rouget, a. a. o. s. 549. 1862 . 
"der Nervenhöcker der Muskelfaser in der That durch eine kugel"haubenförmige Ausstülpung des Sarkolemms gebildet wurde, inner„halb deren die Endplatte lag. Eine Fortsetzung des Sarkolemms „zwischen Nervenhöcker und Muskelinhalt lässt sich jetzt auf keine "Weise erkennen. Der an das Sarkolemm herantretende dunkel„randige Nerv ist nach der Behandlung mit Kalilauge noch deutlich "wahrzunehmen." Engelmann erklärt demgemäss die Endplatten für direkte Fortsetzungen und Ausbreitungen des Achsencylinders. - Die Endplatte geht stetig und, ohne dass ein Zwischenraum vorhanden wäre, in die contractile Substanz über. "Untersucht man „Flächenansichten von Endplatten, die entweder frisch oder nur "kurze Zeit der Einwirkung saurer Flüssigkeiten (stark verdünnte „Essigsäure, Chlorwasserstoffsäure) ausgesetzt waren, so sieht man "die scheibenförmige Endplatte an ihrer Peripherie keineswegs von "einer seharfen Contur ungrenzt, wie dies z. B. Krause zeichnet; "die feinkörnige Substanz verliert sich vielmehr an der Peripherie "der Endplatte ganz allmählich, ohne scharfe Grenze auf der quer"gestreiften Substanz. Nirgends kann man die Stelle bestimmen, "wo die Endplatte aufhört." _ _ „Bei der Betrachtung vollkommen "reiner Profilansichten kann man gleichfalls deutlich erkennen, dass "es keine scharfe Grenze zwischen der unteren Fläche der End"platte und der contractilen Substanz gibt. Endplatte und Muskel„inhalt berühren sich durchaus nicht so, wie etwa Collectorplatte „und Condensatorplatte sich berühren, sondern es findet zwischen „beiden Substanzen ein ununterbrochener, wenn gleich schneller „Uebergang statt.“ 1 )

Wie ich bereits oben darlegte, hat die Substanz des Nervenhügels vielleicht die Bedeutung, die Vermittlung zu bilden für die Uebertragung der Erregung auf die contractile Substanz. Ist das so, dann würde Engelmann's Auffassung als eine berechtigte anerkannt werden müssen. Auffallend bleibt nur, dass der Achsencylinder sofort zu dem mächtigen kernhaltigen Hügel anschwellen soll. Bei den Insecten und doch auch beim Frosche durchbohren die Verästelungen des Achsencylinders den Nervenbügel und werden von seiner Substanz überzogen. Hier ist es schwer, den Nervenhügel als angeschwollenes Ende des Achsencylinders anzusehen. Mir ist es deshalb wahrscheinlich, dass auch bei den Reptilien, Vögeln und

1) Engelmann, a. a. O. S. 28 u. s. w. 
Säugethieren der Achsencylinder den Nervenhügel durchbohrt und mit feinsten Fasern sich in der contractilen Substanz verzweigt.

Dass eine derartige Einrichtung auch am Nervenhügel der Reptilien, Vögel und der Säuger vorhanden ist, geht aus den Untersuchungen Kühne's und seiner Nachfolger hervor, welche den Achsencylinder sich in die protoplasmatische, kerntragende Substanz des Nervenhügels fortsetzen lassen. Diese Fortsetzungen zeichnet W. Kühne wie ein Netz anastomosirender blasser Fäden, welches er mit stumpfen Enden nicht üher die protoplasmatisch-kernige Substanz hinaustreten lässt. Dieses in diese Substanz eingebettete Netz ist also nach $K \ddot{h} h \mathrm{ne}$ das eigentliche Ende des Achsencylinders und wird als motorische Endplatte bezeichnet. Diese Auffassung ist aber von W. Kühne keineswegs hewiesen. Aus seinen eigenen Angaben geht vielmehr nit grosser Wahrscheinlichleit hervor, dass seine motorische Fndplatte ein Kunstproduet ist. Denn am frischen noch lebendigen Muskel von Lacerta agilis gehen nach Kühne's eigener Zeichnung ${ }^{1}$ ) (Fig. $36 c$ ) von der Eintrittsstelle des markhaltigen Nerven in den Hügel blasse anastomosirende Bahnen aus, welche in keiner Weise gegen das Protoplasma ahgegrenzt sind, welches sie durchiehen. Im Laufe des Absterheus treten [siehe Kühne's Fig. 36(c) a. a. ().] ju Nervenhügel nach $K u ̈ h n e$ klare. durchsichtige, bliss contourirte Bläschen auf, 1. h. wohl Tropfen, und die scheinbaren Verüstelungen des Achsencylinders werden immer schärfer und dunkler contourit, wohei es sich wohl um eine Gerinnungserseleinung der perifibrilläreu Substinz der Achsencylinder, um ein Zusammenfliessen der postnurtalen Tropfen handelt. So entsteht demn cin höchst unregelmässiges Netz zerflossener Massen, welehes die sogenannte notorische Fndplatte darstellt, aber doch fast sicher ein Kunstprociuct ist. Wenn man Kühne's Abbildung seiner sogenannten Endplatte, wie sie im wanz frischen Muskel aussieht, vergleicht nit der von Cohnheim ${ }^{2}$ ) nach Silberbehandlung dargestellten Endplatte, so wird man zugeben müssen, dass eine ungeheuer grosse Veränderung der Structur stattgefunden hat. - Von besonderer Wichtigkeit ist Walde yer' $s^{3}$ ) Auqabe, dass man bei

1) W. K ühne; Motorische Nervenendigung lei den Wirbelthieren. Stricker's Uandbuch Bi. 1s. 159.1871.

2) Dr. Cohnheim, Ueler die Endigung des Muskelnerven. Virchow's Archiv Bd. 34 Taf. V Fig. 3 s. 194. 1865.

3) W. Waldeyer, Ueber die Endigung der motorischen Nerven in den quergestreiften Muskeln. Centralbl. f. d. med. Wiss. 18633 \$. 371. 
Ansichten von der Fläche noch eine Zweitheilung, auch Dreitheilung des Achsencylinders schon in dem Bereich der Endplatte auch bei Vertebraten sehen kann. Wir dürfen demnach annehmen, dass sich im Nervenhügel die sich vielfach theilenden Achsencylinder wohl ebenso wie bei Hydrophilus oder Aphodius verhalten. Gibt man dies $\mathrm{zu}$, so tritt überall dasselbe Gesetz für die anatomische Beziehung des motorischen Nerven zur quergestreiften Muskelfaser auf.

Es soll endlich noch hervorgehoben werden, dass der wichtigste Punkt bei dieser Frage, nämlich die Durchbohrung des Sarkolemms durch den Nerven und die intracellulare Endigung des Achsencylinders, auch noch von anderen Autoritäten ersten Ranges bestätigt worden ist, nämlich von W. Waldeyer ${ }^{1}$ ), J. Cohnheim²) und J. Ger$\overline{\mathrm{I} a \mathrm{ch}^{3}}{ }^{3}$. Der Letztere sagt: „Die Muskeln sind als die contractileu "Endausbreitungen der Nerven zu betrachten“. Ich glaube, dass in dieser Auffassung die tiefste Wahrheit liegt, weiss aber, dass sie vor der Hand bei Vielen nur auf Widerspruch stossen wird.

Ich bin also vollkommen mit Engelmann und Gerlach einverstanden, dass der Achsencylinder mit der contractilen Substanz in stetigem organisierten Zusammenhange steht oder dass die Endigung des motorischen Nerven als intramuscular anerkannt werden muss.

F. Frankenhäuser ${ }^{4}$ ) hat zuerst nachgewiesen, dass aus dunkelrandigen Nerven mit einem kernhaltigen Perincurium versehene Fasern hervorgehen, und dass die feinsten Verästelungen der Achsencylinder in die glatten Muskelzellen eindringen und sogar mit den Körnern des Zellkerns sich verbinden. J. Arnold ${ }^{5}$ ) hat in einer sehr eingehenden Untersuchung (siehe Fig. $10 b$ und $c$ ) die

1) W. Waldeyer, Ueber die Endigung der motorischen Nerven in den quergestreiften Muskeln. Medic. Centralb1. 1863 Nr. 24 S. 369, und Zeitschr. f. rat. Medic. Bd. 20 \& 198.

2) J. Cohnheim, Ueber die Enàigung der Muskelnerven. Centralbl. f. d. medic. Wiss. 1863 S. 865.

3) J. Gerlach, Ueber das Verhältniss der nervösen und contractilen Substanz der quergestreiften Muskeln. Archiv f. mikr. Anat. Bd. 13 S. 399.1877.

4) J. Frankenhäuser, Die Nerven der Gebärmutter in den glatten Muskelfasern S. 67. Jena 1867.

5) J. Arnold, Gewebe der organischen Muskeln. Stricker's Handbuch der Lehre von den Geweben Bd. 1 s. 142. Jena 1871. 
Ergebnisse Frankenhäuser's bestätigt, aber hinzugefügt, dass die Körner des Kernes nicht als die wirklichen Endigungen des motorischen Nerven anzusehen seien, als vielmehr Knotenpunkte des feinsten Nervennetzes, was besonders auf Querschnitten der Muskelfasern (Fig. 10c) deutlich hervortritt.

Stefan $A$ pathy ${ }^{x}$ ) hat mit seinen berühmten Methoden zur Darstellung der Neurofibrillen besonders bei Wirbellosen (Pontobdella) bewiesen, dass die Nerven in das Innere der glatten Muskelfasern

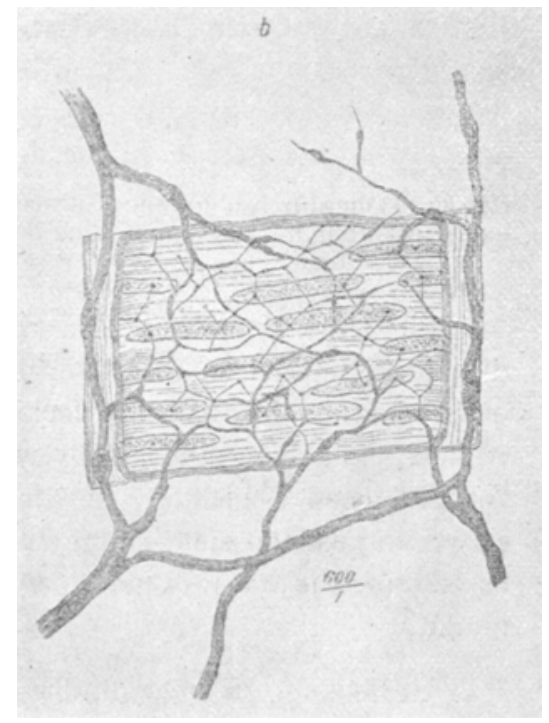

Figg. $10 b$. eindringen, wobei es aber nicht zur Bildung eines Neurofibrillengitters kommt. Die Primitivfibrille spaltet sich bei steter Gabelung in immer dünnere Primitivfibrillen, blejbt aber sehliesslich oft nicht in der Muskelfaser, sondern tritt aus ihr wieder heraus. Leitende Anastomosen zwischen den

Muskelfasern sind besonders leicht nachaweisen. Jedenfalls theilt A pathy aber auch Beohachtungen mit, welche hezeugen, dass viele von den intramuskulären Verästelungen der Neurofibrillen scheinhar frei auslaufen, ähnlich wie es von W. Kühne und Th. W. Engelmann bei den Fröschen heobachtet worden ist.

Fine eigenthümliche Art der Endigung motorischer Nerven an nicht quergestreiften Muskeln ist schon 1840 von $\mathrm{D}$ o y $\mathrm{r}^{\mathrm{r}} \mathrm{e}^{2}$ ) entdeckt

1) Stefan Apathy, Las leitende Elcment lea Nervensystems und seine topographischen Beziehungen zu den Zellen. Mittheilungen aus der zool. Station zu Neapel Bd. 12 S. 685. 1895-1897. - Derselhe, Das leitende Element in den Muskelfasern ron Ascaris. Arch. f. mikrosk. Anat. Bd. 49 \$. 886. 1894.

2) Doyère, Mémoire sur les Tardigrades. Annales des Sciences natur. 2. Serie 1840 (Zoologie), T. 14 p. 346. Pl. 17 Fig. $1-4$. 
worden, wie aus Fig. 11 (nach Greef) erhellt. Es ist die Nervenendigung bei Milnesium tardigradum (Bärthierchen). $M$ Muskelfaser, $K$ Muskelkern, $D$ D o y è re' scher Hügel, $N$ Nerv. Der blasse durchsichtige und nicht körnige Nerv soll sich nach Doy ère in einen feinkörnigen Hügel umwandeln und hiermit die blasse ungetrübte Muskelfaser umgreifen. Neurilemm und Sarkolemm fehlen. Hier wäre also die alte Streitfrage ohne Weiteres gelöst dahin, dass der Nervenhügel nicht auf dem Sarkolemm liegt, weil kein Sarkolemm da ist. Die Entdeckung von M. Doyère ist bald von A. de Quatrefages ${ }^{1}$ ) nicht bloss für die Tardigraden, sondern auch noch für einige Anneliden, Rotatorien und besonders Eolidina bestätigt worden. Quatrefages gibt wie D o yère eine Zeichnung der Nervenendigung, in der der Kern

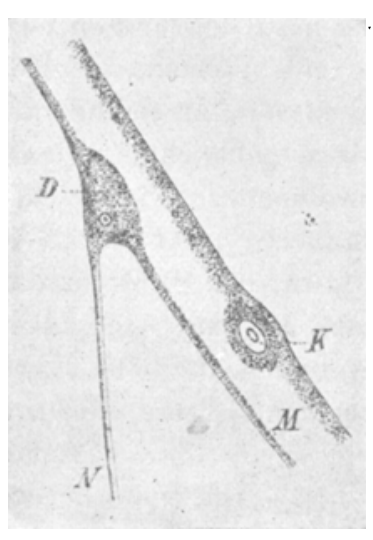

Fig. 11. im Nervenhügel fehlt. Do yère sowohl wie Quatrefages fassen die Beziehung der Nerven zu der Muskelfaser so auf, dass ihre Materie sich gegenseitig durchdringt, „par une pénétration peut-être réciproque, par une véritable fusion de substance."

Eine weitere willkommene Bestätigung D o yère's hat Richard Greef ${ }^{2}$ ) geliefert. Sehr bemerkenswerth ist die Beobachtung Greef's, dass eine Ganglienzelle den peripherischen Verlauf des motorischen Nerven unterbricht. (Siehe Greef's Fig. 3 Taf. IV.) Es handelt sich abgesehen hiervon um Bildungen, wie sie bei den quergestreiften Muskeln der Regel nach vorkommen. Ich vermuthe, dass auch in diesem Fall eine Fortsetzung der Neurofibrillen durch den Nervenhügel noch nachgewiesen werdeil wird.

Unsere Untersuchung hat also auf Grund der von

1) A. de Quatrefages, Annales des Sciences naturelles [2] t. 19 (Zoologie) p. 299.1843.

2) Richard Greef, Ueber das Nervensystem der Bärthierchen, Arctiscoidea C. A. S. Schultze (Tardigraden Doyè re) mit besonderer Berücksichtigung der Muskelnerven und derea Endigungen. Arch. f. mikrosk. Anatomie Bd. 1 S. 101. 1865. - Derselve, Untersuchungen über den Bau und die Naturgeschichte der Bärthierchen. Thidem Bd. 2 S. 102.1866. 
den hervorragendsten Forschern festgestellten Thatsachen bewiesen, dass bei allen Thieren der motorische Nervin die Zellsubstanz der quergestreiften oder glatten Muskelfaser eindringt und darin endigt. Die Continuität der Leitung ist unzweifelhaft.

A. Babuchin ${ }^{1}$ ) hat die merkwürdige Entdeckung gemacht, dass die elektrischen Organe nichts weiter als modifizirte Muskelfasern sind. I. C. $\mathrm{Ewart}^{2}$ ), L. I. I. $\mathrm{Muskens}^{3}$ ) und hesonders Th. W. Engelmann ${ }^{4}$ ) haben den genaueren Entwicklungsgang der elektrischen Organe festgestellt, der sieh besonders gut hei Raja verfolgen lässt.

Die Art, wie die Nerven zu den Platten der elektrischen Organe in Beziehung treten, ist bei den versehiedenen Arten der elektrischen Fische ganz erstaunlich verschieden. Ein ausserordentlich günstiges Object ist das elektrische Organ des Zitterwels, Silurus electricus, auf welches zuerst von Theodor Bilharz ${ }^{5}$ ) in Kairo die Aufmerksamkeit gelenkt worden ist. Max Schultze " hat dann mit bekannter Mcisterschaft den Zitterwels zum Gegenstand einer grossen, äusscrst werthvollen Untersuchung gemacht. Beifolgendes Prïparat Max Schultze's (s. unsere Fig. 12) zeigt, dass der markhaltige Nerv mit der elcktrischen l'latte durch eine gewaltige kegelförnige Anschwellung verbunden ist. Platte und Anschwellung bestehen aus Protoplasma, in welches zahlreiche Kerne eingebettet sind, stellen also ein Syncythium dar, wie die Muskeln. Bei diesem Präparate liegt der änsserst günstige Umstand vor, dass der Nerv in das

1) A. Babuchin, Entwicklung der elektrischen Organe und Bedeuturg der notorischen Endplatten. Vorläufige Mittheilung. Centralbl. f. d. med. Wiss. $1870 \mathrm{Nr} .16$ u. 17.

2) E. C. Fwart, The electric organ of the skate. On the Development of the Electric Organ of Raja batis. Plil. Transact. London. vol. 179 p. $399.1888 .-$ Ueber Faja circularis ibid. p. 410. - Ueber Raja radiata ibid. p. 5:39.

3) L. J. J. Muskens, Zur Kenntniss der eleltrischen Organe. Tydschr. her Nederl. Dierkund. Verecniging. 2. R. 1). IV. 1892.

4) Th. W. Engelinann, Die Blätterschicht der elektrischen Organe von Raja in ibren genetischen Beziehungen zux quergestreiften Muskelsuhstanz. Dies Archiv Bd. 57 \$. 149.1894.

5) Theodor Bilharz, Jas clektrische Organ des Zitterwelses. Lcipzig 1857.

b) Max Schultze, Zur Kenntniss der elektrischen Organe der Fische. Halle 1858. 
Protoplasma des Syneythiums bei a eintaucht, noch ehe er sein Mark verloren hat. Hier kann Niemand leugnen, dass die Nervenendigung intracellular liegt. Max Schultze zeichnet aber an der Stelle, wo der markhaltige Nerv im Protoplasma aufhört, keine Spur eines hervortretenden Achsencylinders, und das hat bei einem so scharfen Beobachter ein gewisses Gewicht. Man müsste also annehmen, dass der Achsencylinder ohne vorherige Verästelung sich unmittelbar in die Substanz der elektrischen Platte fortsetzt. Max Schultze ${ }^{1}$ ) sagt: "Die Nervenfaser ragt öfters aber auch ein „Stückchen in die spindelförmige Anschwellung (a) hinein und zeigt

Fig. 12.

"sich dann rings umgeben von dem blassen Inhalte der An"schwellung. Dies Verhältnis erschwert die Deutung dieses Letzteren „als einfach aus der markhaltigen Faser herausgetretenen Achsen„cylinders. Die feinkörnige Substanz erscheint vielmehr als etwas „Selbständiges neben der Nervenfaser. Dennoch kann ein Zweifel „darüber, dass jene eine unmittelbare Fortsetzung dieser sei, nicht "wohl aufkommen. Beide Substanzen sind in derselben Scheide "eingeschlossen und stehen in inniger Berührung mit einander.

1) Max Schultze, Zur Kenntniss der elektrischen Organe der Fische S. 8. Halle 1858. 
„Unter diesen Umständen liegt es allerdings sehr nahe, anzunehmen, "dass der Achsencylinder als eine eiweissartige fettlose Masse das "Material zu der feinkörnigen Substanz liefere."

Ein weiteres ausgezeichnetes Beispiel der continuirlichen Verbindung des Nerven mit dem Endorgane liefern die pseudoelektrischen Organe bei Raja und Mormyrus. Max Schultze ${ }^{1}$ ) besehreibt dies folgendermaassen: „Die Achsencylinder der Nervenfasern, welche

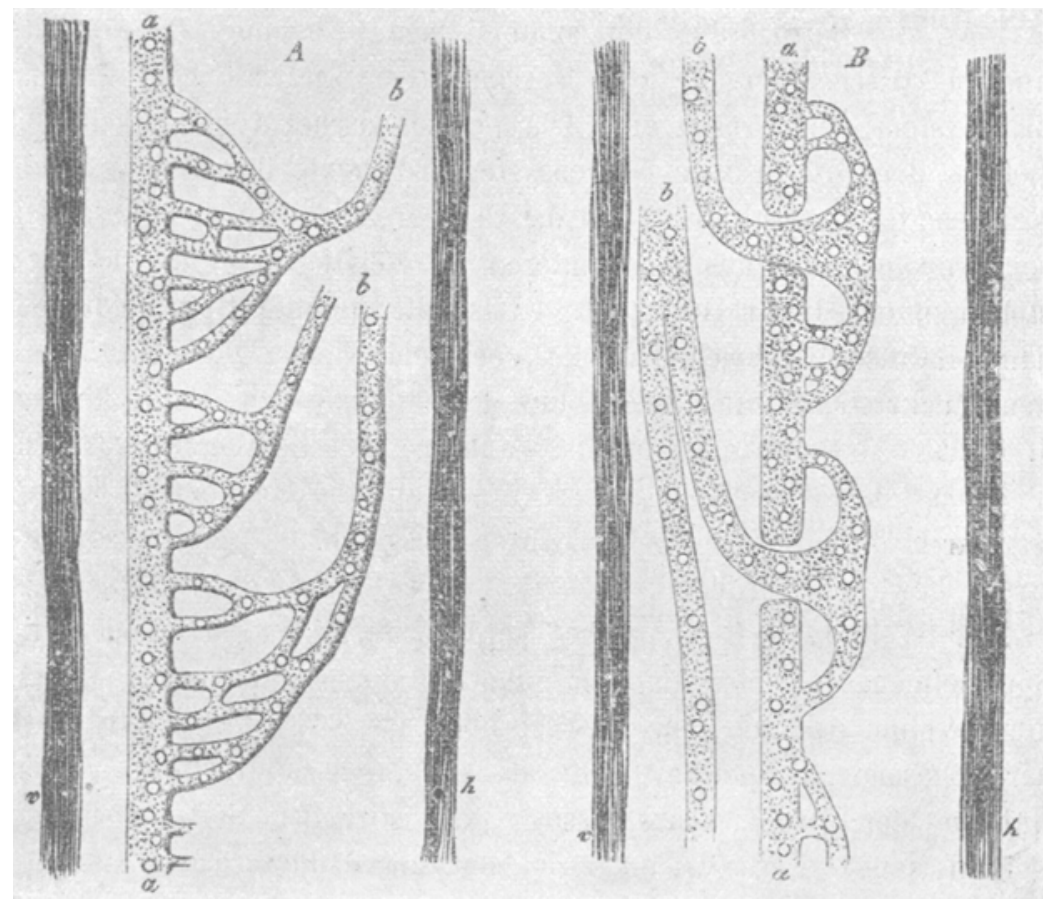

Fig. 19.

diese Organe in Alhängigkeit von den Centralorganen des Nervensystems setzen, endigen hier in den sogenannten clektrischen Platten, das sind direkte Ausbreitungen der Nervenfasern zu ansehnlichen Scheiben, welche je eine in jedem durch hindergewebige Septa abgegrenzten Kästchen der genannten Organe liegen. Wie Fig. 13 zeigt - stellt die elektrische Platte eine directe Ausbreitung der Nervensubstanz dar, wohei es vorkommt, dass die Nervenfasern erst

1) Max Schultze, Allgemeines über Structurelemente des Nervensystems. Stricker's Handbuch Bd. 1 s. 124. 1871. 
durch Löcher der Platte hindurchtreten (einige Mormyrusarten und Malapterurus), elıe sie sich in die Substanz derselben auflösen“. Zur Erklärung der Fig. $A$ : Aus dem elektrischen Organ von Mormyrus oxyrhinchus. Ebenso bei M. longipinnis und cyprinoides, $v$ vorderes, $h$ hinteres bindegewebiges Septum; $a a$ elektrische Platte, $b b$ Nerven, welche sich in dieselbe einsenken. $B$. Aus dem elektrischen Organ von Mormyrus dorsalis.

An die Betrachtung der anatomischen Beziehung der Muskeln und elektrischen Organe zum Nervensysteme schliesst sich zunächst das System der Drüsen an. Die physiologische Abhängigkeit des Lebens der Drüsen vom Nervensystem ist heute durch beweisende Versuche festgestellt. Nicht nur die Drüsen, welehe aus dem äusseren, sondern auch die aus dem inneren Keimblatt sich entwickelnden stehen unter dieser Herrschaft. Das gilt für die Speicheldrüsen, Thränendrüsen, Schweissdrüsen, Leber und Niere (beeinflusst durch den Zuckerstich), und nach den bedeutungsvollen Entdeckungen J. P. Pawlow's ${ }^{1}$ ) auch für das Pankreas und die Magensaftdrüsen.

Dass der Absonderungsnerv direct auf die Drüsenzelle wirkt, ist durch die an den Speicheldrüsen ausgeführten Untersuchungen streng bewiesen worden:

1. Weil durch Reizung der Chorda tympani in kurzer Zeit eine Speichelmenge aus rler Glandula submaxillaris erhalten werden kann, deren Volum das der ganzen Drüse übertrifft, so ist festgestellt, dass der abgesonderte Speichel nicht als ein durch Contraction aus den Gängen der Drüse ausçepresster präexistirender Saft angesehen werden kaun. Das Gleiche wird bewiesen dadurch, dass Reizung der Chorda tympani einen dünnflüssigen, Reizung dés N. sympathicus cervicalis einen dickflüssigen Speichel erzeugt.

2. Dass die durch Chordareizung bedingte starke Vermehrung des Blutstroms in der Drüse nicht die Ursache der Absonderung ist, folgt daraus, dass, wie Rudolf Heidenhain ${ }^{2}$ ) entdeckte, nach

1) J. P. Paw low, Die Arbeit der Verdauungsdrüsen (in's Dentsche übersetzt von D. A. Waiter). Wiesbaden 1898.

2) Rudolf Heidenhain, Ueber die Wirkung einiger Gifte auf die Nerven der Glandula submaxillaris. Dies Archiv Bd. 5 S. 309. 1872. - Derselbe, Einige Versuche an den Speicheldrüsen. Ibidem Bd. 9 S. 395. 1874. - Derselbe, Ueber secretorische und trophische Drüsennerven. Ibidem Bd. 17 S. 1. 1878. Derselhe in L. Hermann's Handbuch der Physiologie Bd. 5 I. Abth. S. 29. 
Atropinvergiftung, die Reizung der Chorda tympani dieselbe Vermehrung des Blutstromes, aber keine Secretion zur Folge hat, während die Reizung des N. sympathicus cervicalis Secretion erzeugt, obwohl der Blutstrom stark geschwächt oder ganz aufgehoben sein kann. Als Ergänzung des Beweises zeigte R. Heidenhain, dass jede Zelle der Gl. submaxillaris von beiden Nerven beeinflusst werden kann.

3. Auch die während der Secretion auftretende Erhitzung der Drüse, sowie die Steigerung des Secretionsdrucks über den Blutdruck bezeugen, dass in der Speichelzelle eine besondere Arbeit sich in Folge der Innervation vollzieht.

Da also ein unmittelbarer Einfluss der Absonderungsnerven auf die Drüsenzelle vorliegt, schloss ich, dass derselhe mit derselben continuirlich zusammenhänge, heziehungsweise mit seinen Fihrillen in sie eindringt. An Priparaten, die ich in Jodserum oder nach anderen Methoden isolirt hatte, wies ich nach, dass markhaltige und marklose Nerven die Tunica propria durehbohren, und dass die Fibrillen des Achsencylinders sich in Fibrillen fortsetzen, welche

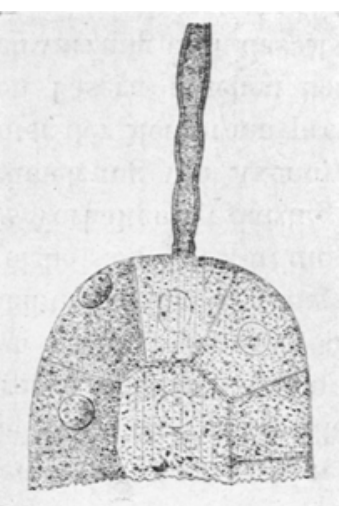

Fig. $14 \ldots 1$.

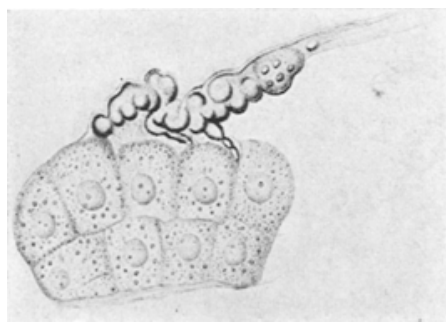

Fig. $14 B$.

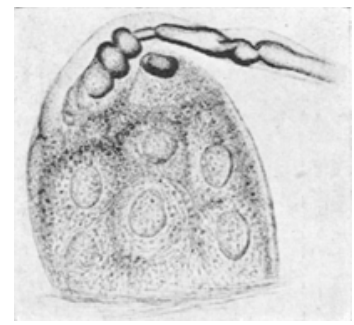

Fig. $14(!$

das Protoplasma der Speichelzelle durchziehen. Der markhaltige Nerv verliert an der Durchbohrungsstelle sein Mark. Beifolgende Figuren 14 erläutern den Zusanmenhang der Nerven mit der Epithelzelle ${ }^{1}$ ).

1) E. F. W. Pflüger, Die Kndigıngen der Absonderungsnerven in den Speicheldrüsen. Bonn 1866. - E. Pflüg er, I)ie Endigungen der Absonderungsnerven in den Speicheldrüsen und die Entwicklung der Epithelien. - Ferner: E. Pflüger, Die Endigungen der Absonderungsnerven im Pankreas. Arch. f. E. I'flüger, Archiv für Physiótoyite. Bd. 112. 


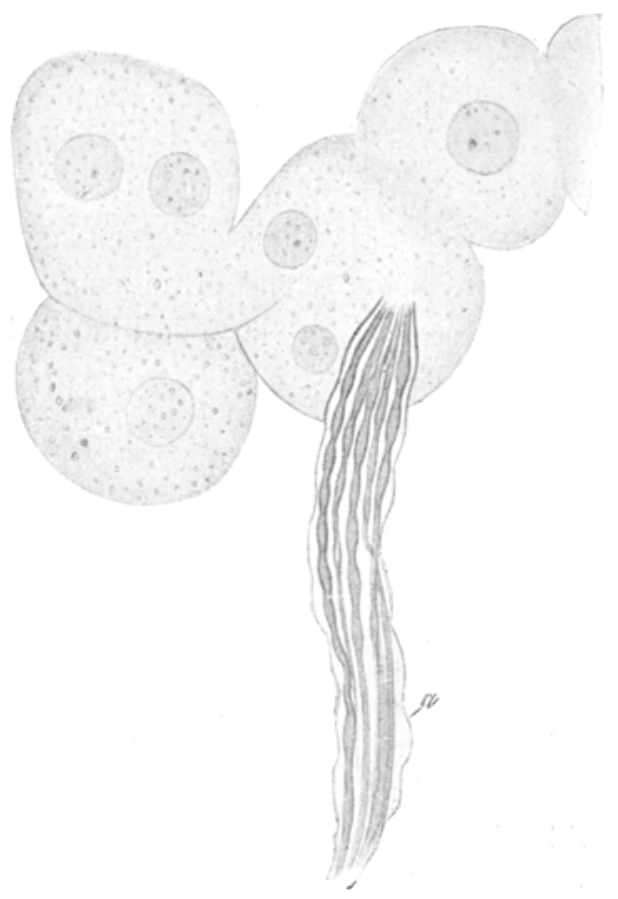

Fig. $15 \mathrm{~A}$.

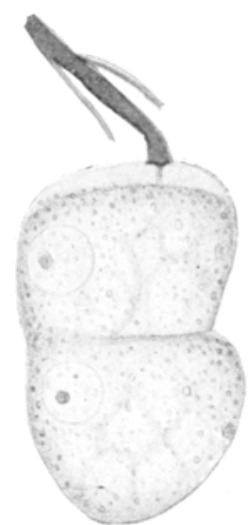

Fig. $15 B$.

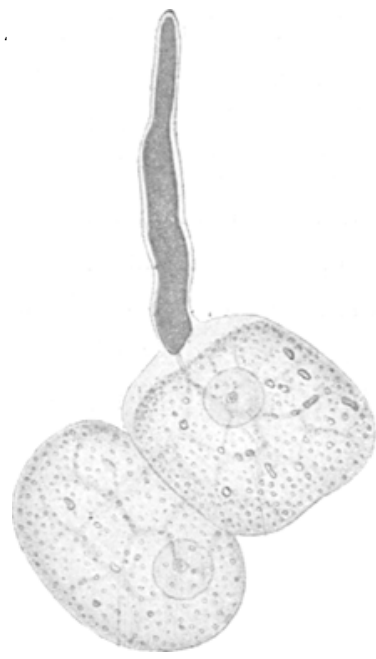

Fig. 15 C.

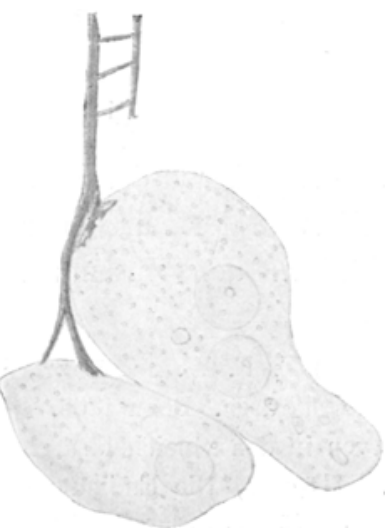

Fig. $15 E$,

Fig. $15 D$. 


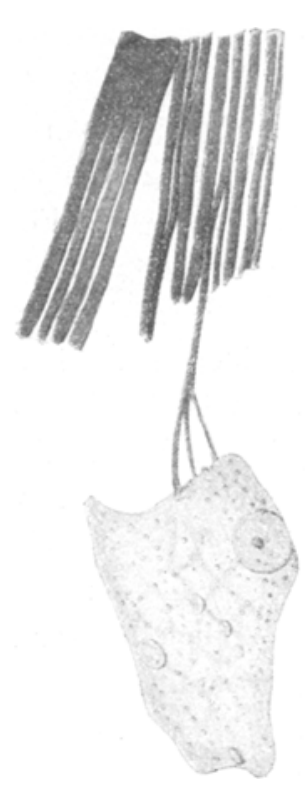

Fig. $15 \mathrm{~F}$.

Es ist wahrscheinlich, dass die Epithelzellen eines Alveolus durch Zellbrücken mit einander verhunden sind. also ein Syncythium bilden; einc einzige zutretende Nervenfaser würde demnach wio bei der Muskelfaser zur Innervation des ganzen Alveolus genügen, - Fig. $14 B$ und $14 C$. Isolirte Alveolen des Kaninchens mit zutretenden markhaltigen Nervenfasern; Fortsetzung des Neurilemms in die

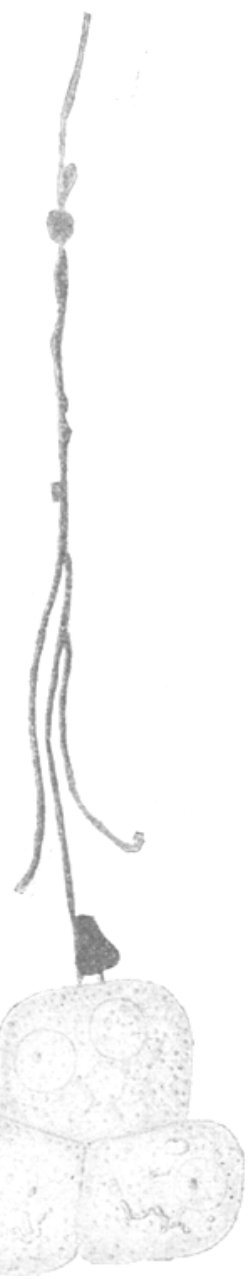

Hig. $15 \%$. M. membrana deutlich. - Verorösserung ca 81\%. Man beachte ferner: besonders beweisende Präparate lieferte mir die Leber, wie beifolgende Fig. 1; bezeugt. Ich habe auf das Gewissenhafteste selbst alle Zeichnungen naturgetreu ausgefüht. Dass die durch Osmiumsäure geschwärzten Fasern und Faserbündel markhaltige

mikrosk. Anatomie Bd. 5 S. 193 u. 199. 1869. - E. Pflüger, Luber die Alhängigkeit der Leber vom Nervensystem. Dies Archiv Bd. 2 S. 459. 1869. F. F. W. Pflüger, Die Speicheldrüsen. Stricker's Handbuch der Lehre von den Geweben Bd. 1 S. 317. 1871. 
Nerven sind, kann Niemand bestreiten; denn wie man sieht, wird kein anderer Gewebetheil geschwärzt. - Wie Fig. $15 \mathrm{G}$ zeigt, quellen an verschiedenen Stellen der Faser Tropfen von Nervenmark hervor, die auch geschwärzt sind. Die einzelnen dünneren Fasern zeigen öfter die zierlichen Varicositäten, was die Fig. $15 A$ recht deutlich zur Anschauung bringt. In einer besonderen manche Einwände widerlegenden Abhandlung habe ich ${ }^{1}$ ) noch genauer die Diagnose dieser Fasern als nervöser Gebilde begründet. Eine grosse Zahl von ganz isolirten Profilpräparaten lässt keinen Zweifel, dass der markhaltige Nerv die Tunica propria der Leberzelle durchbohrt und an der Durchbohrungsstelle sein Mark verliert, genau so wie es beim quergestreiften Muskel der Fall ist. Dies wird bezeugt durch die Figuren $B, C, D$. Dass an der Durehbohrungsstelle der Achsencylinder hervorkommt, um sich in das Protoplasma der Drüsenzelle einzusenken, wird durch dieselben Präparate ausser Zweifel gestellt. Die Präparate $B$ und $C$ zeigen, dass die Achsencylinder in ein zartes feinkörniges Netz übergehen, welches innerhalb der Zellsubstanz liegt.

Zur näheren Erklärung der Figuren 15 ist zu bemerken: $A$ Leberzellen vom Hund mit zutretendem Nervenstämmehen; $B$ Leberzellen vom Pferde mit dünnen, sich theilendem Nerven; $C$ Leberzellen vom Hunde mit Nervenendigung; $D$ dasselbe; $E$ dasselbe; $F$ dasselbe; $G$ Leberzellen vom Hunde mit dünnem, sich theilendem Nerv, an dem durch ausgetretene Marktropfen Varicositäten entstanden sind. Alle Präparate entsprechen einer Vergrösserung von 1100 . -

Eine dankenswerthe erste Bestätigung meiner Angaben über die Endigungen der Drüsennerven lieferte $\mathrm{Franz} \mathrm{Boll}^{2}$ ), welcher das Eindringen markloser und markhaltiger Fasern in die Alveolen der Thränendrüse und ihre Verbindung mit den Epithelien bezeugt. Boll hebt auch hervor, dass er sich bei der Glandula submaxillaris des Kaninchens von dem Eintritt mächtiger markhaltiger Nerven in den Alveolus häufig überzeugt habe.

Die anatomische Beziehung der Nerven zu den Drüsen, die so

1) E. Pflüger, Zum Nachweis der Nervenendigungen in den acinösen Drüsen und der Leber. Dies Archiv Bd. 4 S. 50. 1871.

2) Franz Boll, Ueber den Bau der Thränendrüse. Archiv für mikrosk. Anatomie Bd. 4 S. 146.1868. 
lange streitig gewesen ist, erfuhr dann eine wesentliche Klärung durch Untersuchungen, welche der ausgezeichnete Histiologe C. Kupffer an den Speicheldrüsen von Blatta orientalis angestellt hat. Nach $\mathrm{Kupffer}^{1}$ ) sind diese Drüsen mit einem äusserst weichen Nervenapparat versehen, der wie bei den Säugethieren seine Wurzeln aus zwei Regionen bezieht, nämlich aus dem vom Oberschlundganglion entspringenden Fingeweidenerven und aus dem Bauchstrange. Der Eingeweidenerv giebt, vorüberstreichend, zahlreiche Aeste an die Drüse seiner Seite, die vom Bauchstrange zwischen Untersehlund- und erstem Brustganglion, stammenden Wurzeln ziehen längs des Ausführungsganges dahin und treten mit einerr der Drüse eigentümlichen strangartig entwickelten Gangliensystem in Verbindung, das auch hier enge Beziehungen zu der Scheide der Tracheen zeigt. Zweige des letzteren und der direkt hinzutretenden Nerven bilden nun ein Geflecht, das in den Interstitien der Läppchen und an der Oberfläche des Gesammtorgans sich verbreitet.

„Der Nervenendast erweitert sich in der Regel coniseh „bei der Verbindung mit dem Acinns und dieser Conus mag ,der Fuss des Nerven heissen. An demselben geht die Nerven„scheide sich zeltartig erweiternd, continuirlich in die Propria "des Acinus über, eine structurlose Membran in die andere. "Lie Scheide ist sowohl an den Nervenstämmen, wie an den End„zweigen sehr geräumig für den Inhalt, sodass an den letzteren die "den Nerv zusammensetzenden Fibrillen bali von einander gelockert „sich durch das ganze Rohr der Scheide vertheilen, bald mehr an"einander gedrängt einen kompakteren Achsenstrang herstellen, dass "ein durchsichtiger Raun zwischen Scheide und Achsenstrang frei „bleibt. Stets aber erseheint an diesen Nerven der Achsenstrang "deutlich fibrillär. Zwischen den Fibrillen finden sich namentlich an "den Knotenpunkten der Geflechte, aber auch im Verlauf der Zweige "Kerne mit sie umgebender feinkörniger Masse. Am Fusse der "Nerven erweitert sich der von der Scheide umschlossene Raum noch "etwas mehr und zwischen ihnen findeu sich meist mehrere der "eben erwähnten von Punctmasse umgebenen Kerne. Indem also .die Scheide des Nervenfusses in die Propria des Acinus ubergeht, ..treten die Nervenfibrillen unmittelbar an die 1-2 Drüsenzellen heran.

1) C. Ku pffer, Das Verhältniss von Drüsennerven zu Drüsenzellen. Arch. f. mikrosk. Anatomie Bd. 9 S. 387.1872. 
„Alle diese Verhältnisse: der Nervenreichthum überhaupt, die „zahlreichen an die Läppchen herantretenden Nerven, das Ver„schmelzen der Nervenscheide mit der Propria und das Eindringen „der Nervenfibrillen in das Innere des Acinus lassen sich an den. "Speicheldrüsen der Blatta orientalis leicht beobachten. Fine be„sondere Präparation der Drüse ist hierzu kaum erforderlich." Kupffer empfiehlt die Behandlung mit Osmiumsäuredämpfen nach Hensen's Vorgang (Archiv für Ohrenheilkunde Bd. 6 S. 30) und gibt genauere im Original nachzulesende Vorschriften. C. Kupffer betont, dass dieses Untersuchungsobject die Fundamentalfragen dieser Controverse endgiltig löst. Zur genaueren Feststellung der Beziehung der Nervenfibrillen zu den Drüsenzellen empfiehlt C. Kupffer die frische Drüse unter Jodserum zu untersuchen. Es tritt dann eine Lockerung zwischen der Propria und den Drüsenzellen ein und durch leichten Zug an dem Nerven, dureh Verschieben des Deckglases bewirkt, kann man den Raum innerhalb der zeltförmigen Erhebung der Propria vergrössern, so dass der Verlauf der Nervenfasern vollkommen übersehen werden kann. Bei 800 maliger Vergrösserung überzeugt man sich, dass der grösste Theil der Fibrillen nach dem Eintritt in den Acinus an den nächsten Zellen vorüber in's Innere streicht; in die mit freier Aussenfläche vorliegenden Zellen treten nur ganz wenige, je 2 bis 4 isolirte Fibrillen ein. "Diese verschmelzen nicht derart mit der Substanz „der Zelle am Berührungspunkte, wie man sich früher etwa das. "Verhältniss zwischen Achsencylinder und Nervenzelle vorstellte, ehe "Max Schultze auf den fibrillären Bau der Achsencylinder auf"merksam gemacht hatte, sondern der freie Faden lässt sich als "solcher noch eine Strecke weit in die Zelle hinein verfolgen, „ist also von der Substanz, in die er eingebettet ist, diffe"renzirt." C. Kupffer stellte endlich noch fest, dass die Nervenfibrille nach dem Eintritt in die Zelle sich noch weiter theilt. Er sagt: „Mit Sicherheit habe ich mehrmals eine zweimalige „gabelförmige Spaltung auf der halben Strecke von der Peri„pherie der Zelle bis zum Centrum derselben wahrgenommen."

C. Kupffer ${ }^{1}$ ) hat seine Untersuchungen über die Speichel-

1) C. Kupffer in Kiel, Die Speicheldrüsen von Periplaneta Blatta orientalis und ihr Nervenapparat. Taf. IX S. LXIV in Beiträge zur Anatomie und Physiologie als Festgabe Carl Ludwig zum 15. October 1874 gewidmet von. seinen Schülern. Leipzig 1875. 
drüsen von Blatta orientalis fortgesetzt und in der am 15. October 1874 dem Physiologen Carl Ludwig zum 25jährigen ProfessorenJubiläum gewidmeten Festschrift veröffentlicht. C. Kupffer stellt hier fest, dass die Nerven die Membrana propria durchbohren, dann in die Drüsenzellen eindringen, sich noch intracellular wiederholt theilen und mit einem Reticulum versehmelzen. Die beistehende Fig. 15 nach $\mathrm{K}$ upffer erläutert die Verhältnisse. Es sind zwei Zellen eines Acinus in Verbindung mit einem Endnerv nach Be-

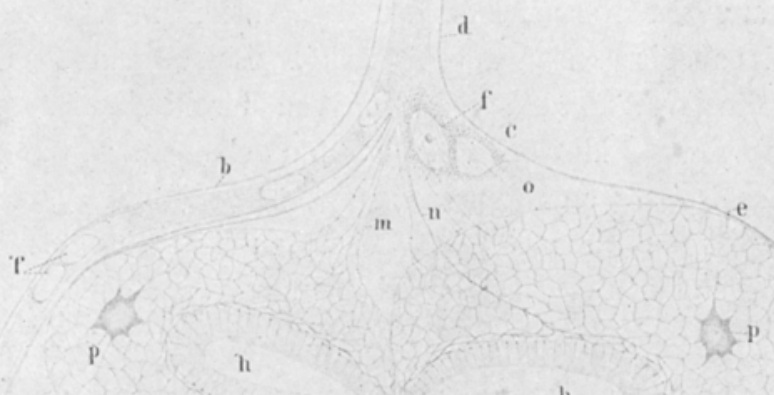

Iig. 16 .

handlung mit Kali. Vergr. (a) 1300. I)ie Grundsuhstanz der Kellen ist gequollen und wasserhell; das Gitter durchsetzt den ganzen Raum beider Zellen.

a Nerv; $b$ weiter laufender, umspinnender Zweig desselhen; c Fuss eines Endnerven; d Nervenscheide, continuirlich in $r$ die Membrana propria des Acinus ühergehend; f Nervenkcrne; $h$ Kapsel mit hyaliner gequollener Wand, die gestrichelt erscheint durch feine sio durchsetzende, von dem Gitter ausgehende Fädchen; diese Kapsel ist eine Grube in der Speichelzelle, welche von einer verdickten Wand tapezirt ist und sich in das Secretionsröhrchen fortsetzt; dieses $i$ Cuticularröhrehen, in das die „Kapseln" zweier Speichel- 
zellen einmünden; $m, n, o$, Nervenfibrillen, isolirt durch den freien Raum, zwischen Nervenscheide resp. Propria und den beiden Zellen verlaufend. Die Fibrille $n$ ist bis in die Nähe der Kapsel zu verfolgen. Die Fibrillen o treten aus der Ebene des Bildes hinaus; $p$ durch Einwirkung des Kali zackig gewordene Kerne der beiden Zellen mit zahlreichen Fäden dem Gitter verbunden.

Kupffer bemerkt nun: „Bereits vor einiger Zeit habe ich "auf die interessanten Verhältnisse an der Speicheldrüse von Blatta "orientalis (Arch. f. mikrosk. Anat. Bd. 9 S. 387) aufmerksam ge"macht und dieselbe als Demonstrationsobject empfohlen, um den "Zusammenhang der Nerven mit den Drüsenelementen darzuthun.

"Hierbei handelt es sich um Zweierlei. Einmal um den Nach"weis, dass die Nervenfäserchen in den von der Membrana propria „der Endläppchen umschlossenen Binnenraum gelangen, und zweitens, „um das Verhältniss dieser feinen Fäserchen zu den Drüsenzellen. "Das Erstere ist an diesem Object leicht zu beobachten, und ich "habe seit der Publication meiner Mittheilung von mehreren Seiten "die Bestätigung meiner Angabe erhalten." - Ferner: "An der "Speicheldrüse von Blatta gelingt es mir unter ge"wissen Cautelen jedes Mal", d. h. mit Sicherheit zu entscheiden, "dass die Nervenfaser sich mit der secernirenden Zelle un"mittelbar verbindet." (A. a. O. S. 65.)

Alle grundsätzlich wichtigen Verhältnisse, welche ich bei den Säugethieren für die Endigung der Nerven in den Drüsen festgestellt hatte, sind also für die Säugethiere von Franz Boll und bei Blatta orientalis von C. Kupffer bestätigt worden. Es handelt sich darum, dass der Nerv die Membrana propria des Alveolus durchbohrt, dass das Neurilemm nnmittelbar sich in die Membrana propria fortsetzt, dass die Nervenfibrillen in die Substanz der Drüsenzelle eindringen und sich hier verästeln.

Wenn man bedenkt, dass ich bei der Veröffentlichung meiner Untersuchungen im Jahre $1866^{\circ}$ bis 1871 doch nicht wissen konnte, welche Ergebnisse F. Boll und C. Kupffer nach mir bekannt machen würden, so gibt es keine Berechtigung, mir zu bestreiten, dass meine Beschreibung der Nervenendigungen in den Drüsen vollkommen der Wahrheit entsprach, trotz der mir gewordenen Anfeindungen.

Zu jener Zeit, d. h. einige Jahre nach Kupffer's Veröffentlichungen, arbeitete bei mir mein morphologischer Assistent, der mir 
von zuständiger Seite als gewandter Mikroskopiker empfohlen worden war, über die Nervenendigungen in den Speicheldrüsen von Blatta orientalis. Obwohl Er viele Monate sich eifrigst mit der Frage beschäftigte, brachte er nicht ein einziges Präparat zu Stande, welches die Beziehung der Nervenfibrillen zur Speichelzelle gezeigt hätte. Und dabei ist gerade die Speicheldrüse von Blatta orientalis, wie C. Kupffer bewiesen hat und hervorhebt, ein zur Eutscheidung der hier in Betracht kommenden Fragen ganz vorzügliches Object. Wie meinem morphologischen Assistenten erging es noch mehreren anderen Forschern. Die Unfähigen, denen ein Zweifel an ihrer eigenen Selbstherrlichkeit als crimen laesae majestatis erscheint. rechtfertigen sich am liebsten, indem sie die Frgebnisse der erfolgreichen Forscher als gröbste Irrthümer verdächtigen, als Verwechselungen von Nerven mit zerflossenem Fett oder Schleim oder Blutvefässen. Solche Verdächtigungen entwerthen, wenn sie auch soch so ungerecht sind, die heste Arbeit auf um so längere Zeit, je qrössere Geschicklichkeit und Ausdauer die Nachuntersuchung verlangt.

Seit der Zeit. wo ich, F. Boll und C. Kupffer über die Endigungen der Drüsennerven arbeiteten, hat die Technik der mikroskopischen Anatomie grosse Fortschritte gemacht. Vor Allem ist hier die Methode von Stefan Apathy hervorzuhehen, welche den Verlauf der Nervenfibrillen mit einer idealen Deutlichkeit zu verfolgen ermöglicht.

Nachdem auch Stefan Apathy ${ }^{1}$ ) mit Hülfe dieser Methode bezeugt hat, dass die Neurofibrillen in die Drüsenzellen eindringen und sie nicht bloss umspinnen, dürfte kein Zweifel mehr an dem Satze berechtigt sein, dass die Absonderungsnerven in der absondernden Zelle intracellular endigen.

Ich glaule hierbei besonders darauf hinweisen zu müssen, dass bis jetzt kein Object vorliegt und keine Methode mikroskopischer Technik, welche den Zusammenhang des Achsencylinders mit dem Protoplasma der Zellen so deutlich zeigt, wie das meine Methode gestattet. Nur der Ursprung des Achsencylinders aus der motorischen Zelle der Vorderhörner des Rückenmarks bietet ein ebenso gutes, ja noch besseres Beispiel. Die Methode von Stefan Apathy bringt den Verlauf der Neurofibrillen mit solcher wunderbarer Schärfe zum Ausdruck, weil sie alle anderen Gewebsdifferentiationen fast bis zum

1) Stefan Apathy, a. a. O. Bd. 12 S. 502, 50.5, 511. 
Verschwinden der letzteren durchsichtig macht. Ich glaube desshalb, dass in den Präparaten von A path y Manches nicht zur Anschauung kommt, welches die Beziehung der Neurofibrillen zum Zellenprotoplasma darstellen würde.

Ich gebe mich nun gleichwohl nicht der Hoffnung hin, den Widerspruch einiger Ultraneuronisten gegen die intracellulare Endigung der Neurofibrillen vollkommen zum Schweigen gebracht zu haben. Diesen Gegnern will ich den Beweis liefern, dass sie mit grösster Parteilichkeit Alles aus der Wissenschaft auszumerzen suchen, was ihnen nicht in den Kram passt. Man nehme das neueste Lehrbuch der Histologie von 1905, das der Würzburger Anatom Dr. Philipp Stöhr in nunmehr elfter Auflage herausgegeben hat. Er bat den Muth, S. 199 die Endigung des motorischen Nerven in den Muskeln folgender Maassen zu charakterisiren:

"Von den Zweigen (Nervenfaserbündeln) entspringen feine, aus „einer Nervenfaser hestehende Aestchen, die sich endlich mit je "einer Muskelfaser verbinden. Dies geschieht in der Weise, dass die „bis dahin noch markhaltige Nervenfaser sich zuspitzt uni unter "Verlust ihrer Markscheide sich anf die Muskelfaser auflegt; „dabei zerfällt der Achsencylinder in leicht gewundene, kolbig an„geschwollene Endästehen, welche die sogenannte motorische (End-) „Platte bilden und auf einer rundlichen, feinkörnigen, zahlreiche „bläschenförmige Kerne enthaltenden Scheibe gelegen sind. Jede "Mnskelfaser besitzt mindestens eine motorische Platte, die ,auf dem Sarkolemm liegt.

„Die an die glatten Muskeln tretenden Nerven bilden ein Ge"flecht, aus dem marklose Nervenfaserbündel hervorgehen; letztere "theilen sich wiederholt und bilden mehrfache Netze, aus dem feinste „Nervenfäserchen entspringen. Diese legen sich an die glatten "Muskelfasern an und sind dort oft mit einer kleinen Ver,dickung versehen; wahrscheinlich besitzt jede Muskelfaser eine "Nervenendigung."

Der Fettdruck der betreffenden Stellen befindet sich nicht im Original, sondern ist von mir veranlasst.

Wenn in den Naturwissenschaften eine Thatsache durch positive Beobachtung Seitens einer Autorität ersten Ranges, welche darauf eine eingehende Untersuchung gerichtet hat, entdeckt wird, wenn dann dieselbe Thatsache nicht von einer, sondern von einer ganzen Reihe von Autoritäten ersten Ranges auf Grund gründlichster Forschung: 
vollkommen bestätigt wird; - wenn dies gilt für die intracellulare Endigung des motorischen Nerven in der quergestreiften Muskelfaser, wenn dies festgestellt ist durch die besten Vertreter unserer Wissenschaft, wie W. Kühne, M. Rouget, Th. W. Engelmann, W. Waldeyer, J. Cohnheim, J. Gerlach, Frankenhäuser, J. Arnold, St. Apathy und Andere, welche Berechtigung hat Philipp Stöhr, seine gegentheilige Ansicht so sehr als maassgebend hinzustellen, dass Er nicht einmal für nöthig findet, auf die abweichenden Ansichten von jenen Forschern ersten Ranges hinzuweisen, dass Er in einer der wichtigsten Fragen der Histologie den Studirenden der Medicin Irrthümer einimpft, ohne dass sie aus der Darstellung irgendwie auf die Unsicherheit der vorgetragenen Lehre aufmerksam gemacht werden. Stöhr hat sich offenbar gedlacht, lass die Neuronentheorie zur Consequenz der Contiguität in allen Fällen führe. Nein! Hieran geht eben die Neuronentheorie zu Grunde.

Wenn die hervorragenden Leistungen so vieler Forscher ersten Ranges, welehe die Endigungen der motorischen Nerven festgestellt haben, von Philipp Stöhr als Dunst behaudelt werden, kann ich mich nicht wundern, wenn meine, Boll's, Kupffer's und Apathy's Arheiten über die Endigungen der Drüsennerven demselhen Schicksal in noch entsehiedenerer Weise anheinfallen. Denn in dem Lehrbuch ron Philipp Stölr wird von den Endigungen der Nerven in den Drüsen gar nicht gesprochen.

Ich babe bisher allerdings vorausgesetzt und doch wohl voraussetzen müssen, dass die wichtigen Arbeiteu jener Autoritäten dem Verfasser des besprochenen Lehrbuches, Ph. Stöhr, nicht unbekannt geblieben sind.

Idh wende mich jetzt zu einer Gruppe von Organen, die ebenfalls unter die Herrsehaft des centrifugalen Nervensystemes gestellt ist und ausgezeichnete Zeugnisse zur Entscheidung unserer Streitfrage liefert. Es sind die Chromatophoren, die Pigmentzellen der Haut.

Ernst Brücke ${ }^{1}$ ) lenkte zuerst in seiner Arbeit über den Farbenwechsel des Chamäleons die Aufmerksankeit auf den Einfluss

1) Ernst Brücke, Ueber den Farbenwechsel des afrikanischen chamäleous. 1852. Auch als Nr. 4:3 von Ostwald's Classiker, Merausgegeben von M. v. Frey $\$ .48$ u. s. w. Leipzig 189? - Derselbe, Kaiserl. Akad. đ. Wiss. in Wien Bit. \& S. 198. 
des Nervensystems und machte auf die Contractionsfähigkeit der sternförmigen Pigmentzellen in der Froschhaut aufmerksam, was durch Harless ${ }^{1}$ ), Lister ${ }^{2}$ ), v. Wittich ${ }^{3}$ ), Virchow ${ }^{4}$ ), Lothar Meyer ${ }^{5}$ ) u. A. im Allgemeinen bestätigt worden ist.

Eine unter der Leitung von Goltz ausgeführte sehr werthvolle Untersuchung von E. H. Bimmermann ${ }^{6}$ ) hat den von allen Beobachtern angenommenen Einfluss des Nervensystemes noch weiter begründet. Durch die Versuche der Nervendurchschneidung und der elektrischen, mechanischen und chemischen Reizung des peripherischen Stumpfes des Nerven wurde bewiesen, dass der Farbenwechsel vom centralen Nervensystem beeinflusst wird; die Durchschneidung des Rückenmarks und die Reizung desselben vermittelst der Elektricität, der Verblutung des Thieres und des Strychnins bewiesen Dies auf's Deutlichste. Bimmermann stellte ferner fest, dass auch auf reflectorischem Wege Farbenveränderungen in der Froschhaut eintreten können, weil Reizung des centralen Endes der durchschnittenen Ischiadicuswurzeln ein Hellerwerden aller nicht gelähmten Hautbezirke bewirkte, wodurch die gelähmte Extremität noch dunkler erschien, als sie vorher war. Bimmermann verlegt das Centralorgan für den Farbenwechsel der Frösche durch die Medulla oblongata und die ganze Länge des Rückenmarkes.

Der Farbenwechsel der Frösche ist dann noch in sehr umfassender und gründlicher Art von W. Biedermann untersucht worden, unter besonderer Berücksichtigung der Innervation der Chromatophoren. W. Biedermann ${ }^{7}$ ) bestätigt die „motorische“ Be-

1) Harless, Ueber die Chromatophoren des Frosches. Zeitschr. f. wissensch. Zool. Bd. 5 S. 372.1853.

2) J. Lister, On the Cutaneous Pigmentary System of the Frog. London Phil. Transact. vol. 148 p. 627.1858.

3) D. v. Wittich, Die grüne Farbe der Haut unserer Frösche. Müller's Archiv 1854 S. 41. - Derselbe, Entgegnung auf Herrn Harless': „Ueber die Chromatophoren des Frosches". Ibidem S. 257.

4) R. Virchow, Chromatophoren beim Frosch. Virchow's Archiv Bu. 1858 S. 266.

5) Lothar Meyer, Ueber die Abhängigkeit der Gefässe und Pigmentzellen vom Nerveneinfluss. Virchow's Archiv Bd. 1853 S. 581.

6) E. H. Bimmerma nn, Ueber den Einfluss der Nerven auf die Pigmentzellen des Frosches. Inaug.-Diss. Strassburg 1878.

7) W. Biedermann, Ueber den Farbenwechsel der Frösche. Dieses Archiv Bd. 51 S. 488.1892. 
ziehung der Nerven zu den Chromatophoren und ebenso die Bedeutung einzelner Gehirntheile für dieselben in Ergänzung der Untersuchungen Steiner's ') und Anderer.

Durch diese ist also die physiologische Beziehung des Nervensystems zu den Chromatophoren über allen Zweifel sicher gestellt

Hier interessirt uns nun in erster Linie, wie sich die anatomische Beziehung der Nerven zu den Pigmentzellen gestaltet. Der erste Forscher, welcher darüber berichtet hat, ist Ley i $\mathrm{g}^{2}$ ), der sich mit Bezug auf Schlangen und Eidechsen darüber folgendermassen auslässt: „Noch glaube ich auch hier (nämlich bei den Schlangen) be„obachtet zu haben, dass ein Theil der Endausläufer (der Nerven) „sich mit den Chromatophoren verbindet; die Nervensubstanz meht unmittelbar in das contractile Protoplasma "über, ähnlich wie bei Protozoen die contractile Leibessubstanz „die sensible Materie des Körpers vertritt. Bei den Lacerten sah „ich, wie schon anderwärts erwähnt wurde, nicht minder, dass „Nervenfasern und Chromatophoren schliesslich in eins zusammen"fliessen können." In seinem grossen Werk über die in Deutschland lebenden Arten der Saurier beschreibt er $^{3}$ ) für Lacerta agilis ein in der Haut gelegenes Nervennetz, aus dem "Ausläufer mit dlen "Zacken der schwarzen Pigmentzellen oder Chromatophoren sich „verbinden."

Die Frage ist dann von Dr. Salomou Ehrmann ${ }^{4}$ ) zum Gegenstande einer eingehenden Untersuchung gemacht worden, die er im Wiener physiologischen Institute ausgeführt hat. S. Eh r man $n$ behandelte die Froschhaut mit einer Lösung von 0,1\% Goldchlorid während 12 Stunden und dann nach Abwaschen 24 Stunden in Prichard'scher Flüssigkeit im Lichte zur Erzielung der Reduction. Die Nervenfasern erscheinen dann am schönsten gefärbt: gesättigt purpurn bis violett. Es handelt sich um markhaltige

1) J. Steiner, Die Functionen des Centralnervensystems und ihre l'hylogenese. Abth. I. Untersuchungen über die Physiologie des Froschhirns S. 29. 1885 .

2) Franz Leydig, Ueber die äusseren Bedeckungen der Reptilien und Imphibien. Archiv f. mikrosk. Anatomie Bd. 9 S. 779.

3) Franz Leydig, Ueber die in Deutschland lebenden Arten der Saurier, S. 7. Tübingen 1872.

4) Dr. Sa lom on Ehrmann. Ueber Nervenendigungen in den Pigmentzellen der Froschhaut. Kaiserl. Akad. d. Wiss. III. Abth. Bd. 84. 1881. 
Nervenfasern, die aber allmählich ihr Mark verlieren und als marklose Fasern in einen breiten Fortsatz der Pigmentzelle übergehen. Wie die beifolgende aus Ehrmann's Abhandlung mitgetheilte Fig. 17 zeigt, ist die Verbindung so massiv, dass an der Continuität nicht gezweifelt werden kann.

Da Franz Leydig bereits die continuirliche Verbindung des Nerven mit den Pigmentzellen entdeckt und bescbrieben hatte und da Ernst Brücke es für geeignet an$\mathrm{sah}$, die in seinem Institute ausgearbeitete Abhandlung $\mathrm{Ehr}$ mann's am 2. Juni 1881 der Kaiserlichen Akademie der Wissenschaften mitzutheilen, darf man die wichtige Thatsache als gesichert ansehen.

Wir wenden uns jetzt zu der Beziehung des Nervensystemes zu den Flimmerepithelien. Die Physiologie dieses Gebietes ist von Th. W. Engelmann ${ }^{1}$ ) einer sehr eingehenden Untersuchung unterworfen worden. In der Achse der cylindrischen Flimmerzelle steigt ein feiner Faden empor und spaltet sich plötzlich in einen Pinsel starrer Fäden, die gegen die flimmernde Oberfläche der Zelle emporsteigen. Nachdem Th. W. Engelmann gefunden hatte, dass die Bewegung der Flimmerhaare durch Chemikalien, Wärme, Elektricität angeregt werden kann, legte er sich die Frage vor, ob der Fibrillenpinsel, der möglicher Weise mit den Flimmerhaaren in Verbindung steht, nervöser Natur sei, Engel-

1) Th. W. Engelmann, Contractilität und Doppelbrechung. Dies Archiv Bd. 11 S. 452. 1875. - Derselbe, Flimmeruhr and Flimmermühle. Ibidem. Bd. 15 S. 493. 1877. - Derselbe, Zur Anatomie und Physiologie der Flimmerzellen. Ibid. Bd. 23 S. 505. 1880.

Fig. 17. 
mann glaubt Dies nicht annehmen zu können, weil die Starrheit des Faserpinsels sich zu entschieden von der Natur von Nervenfibrillen unterscheide.

Stefan Apathy ${ }^{1}$ ) hestätigte Th. W. Engelmann's Ergebnisse vollauf, stellte mit seiner Methode den Fibrillenpinsel dar, erklärt denselben aber für nervöser Natur. Ich gebe hier wieder zur Erleichterung des Verständnisses die etwas schematisch gehaltene Figur 18 (Apathy's Taf. 32 Fig. 5). Das Urtheil dieses Meisters der mikroskopischen Technik hat selbstverständlich ein grosses Gewicht. Ich würde mich auch nicht an der Starrheit der P'inselfasern stossen, welche durch eine Verhornung der perifibrillären Substanzhüllen hedingt sein könnte. So besehreibt Haycraft, worüber ich später berichte, in den Kernen der Epithelzellen der Haut der Schildkröte endigende Fasern, die offenbar nervös sind, aber gerade vor der Endigung eine eigenthümliche Starrheit zeigen, die ich auf Rechnung der perifibrillären Hülle setze. Von ganz hervorragender Wichtigkeit ist nun aber, dass Stefan Apathy in diesem Falle nicht im stande war, wie er ausdrücklich hervorhebt, zu beobachten, dass die Neurofibrillen von aussen in fie Epithelzelle eindringen. Fr sah leicht. wie die Nervenfasern zwisehen den Epithelzellen aufstiegen und sich hier verästelten. Nach A pathy bilden die Nerven ein intercelluläres, intraepitheliales Neurofibrillengitter und aus diesem stammen die fraglichen Gebilde, welche in der Zelle mit einer um so grösseren Deutlichkeit zu sehen sind, und welche für ein System von intracellulüren Neurofibrillen von ilım angesehen werden. Ich

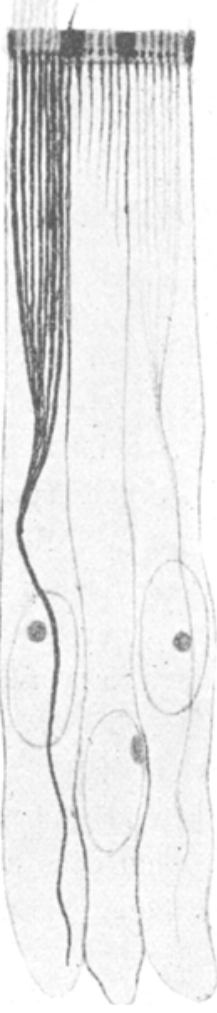

Fig. 1s. muss bekemnen, dass Vieles für die Richtigkeit dieser Auffassung sprieht. Denn wenn man bedenkt, dass die Flimmerepithelien Stoffe

1) Stefan Apathy, Das leitende Element in den Flimmerzellen. Mittheilungen aus der zoolog. Station zu Neapel Bd. 12 S. 697. 1895-1897. 
über Schleimhautflächen bewegen, auch wohl Schädlichkeiten entfernen, hat es etwas Einladendes, dass die Arbeit dieser Zellen unter die Herrschaft des Nervensystemes gestellt ist.

Viel wichtiger aber als diese ganze Frage ist hier die Thatsache, dass zwischen dem intercellulären Fibrillengitter und dem intracellularen Neurofibrillenapparat Züge von Neurofibrillen verlaufen, welche mit Hülfe der Methode Apathy nicht dargestellt werden können. $Z$ wischen dem intracellularen Fibrillengitter der centralen Ganglienzelle und dem Protoplasma derselben können desshalbebenfalls solche nach Apathy's nicht darstellbare Beziehungen existiren, die ich in seinen Präparaten vermisse.

Als gesichert kann also die Beziehung des Nerven zur Flimmerzelle nicht gelten.

Ich gehe nunmehr zur Betrachtung der anatomischen Beziehungen uber, welche zwischen den centripetalen Nervenfasern und ihren Endapparaten nachgewiesen sind. Ich werde nicht auf die scheinbar freien Nervenendigungen eingehen, sondern nur auf die Sinneszellen, welche bei dieser Frage ja allein in Betracht kommen. Auch hier will ich Alles bei Seite lassen, was nicht absolut sicher festgestellt ist.

Unbestritten ist, dass zweierlei Arten von Zellen in der Regio. olfactoria vorkommen, und dass eine Art, welche die Sinneszellen, die „Riechzellen“, darstellt, sich continuirlich in eine Nervenfaser fortsetzt.

Nachstehende Figur 19 nach dem Entdecker Max Schultze ${ }^{1}$ ), bezeugt Dies und zeigt die zierlichen, spindelförmigen, den Achsencylinder charakterisirenden Varicositäten. Es ist ein Präparat vom Menschen.

Als zweites Beispiel wähle ich die Endigung des Acusticus, wie sie von einem anderen grossen Anatomen, nämlich W. Walde yer ${ }^{2}$, in folgendem Präparate (unsere Figur 20) zur Anschauung gebracht

1) Max Schultze, Untersuchungen über den Bau der Nasenschleimhaut. Halle 1862.

2) W. Waldeyer', Hörnerv und Schnecke. Stricker's Handbuch Bd. $z$ s. 949.1872 . 
worden ist. In der Figur bedeutet a Cuticula (Durchschnitt der Lamina reticularis); $b$ Haarzellen; $d$ Körnerschicht; $e$ Nervenbündel; $f$ durchtretende Nervenfaser; $f$ eine solche, welche mit einer Haarzelle verschmilzt; $k$ querdurchschnittenes Blutgefäss. W. Waldeyer hebt noch besonders hervor: "Sowohl bei Vögeln \#als bei Fröschen hat nun $\mathrm{Hasse}^{1}$ ) als erste sichere Beobachtung

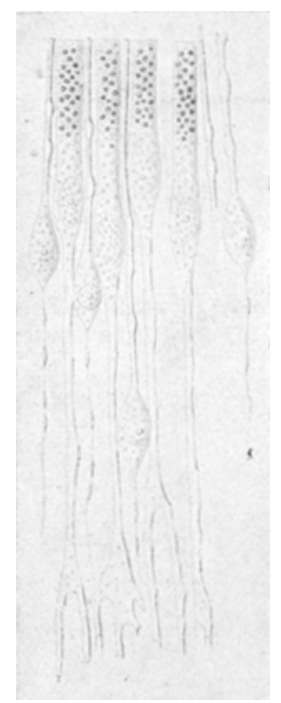

Fig. 19.

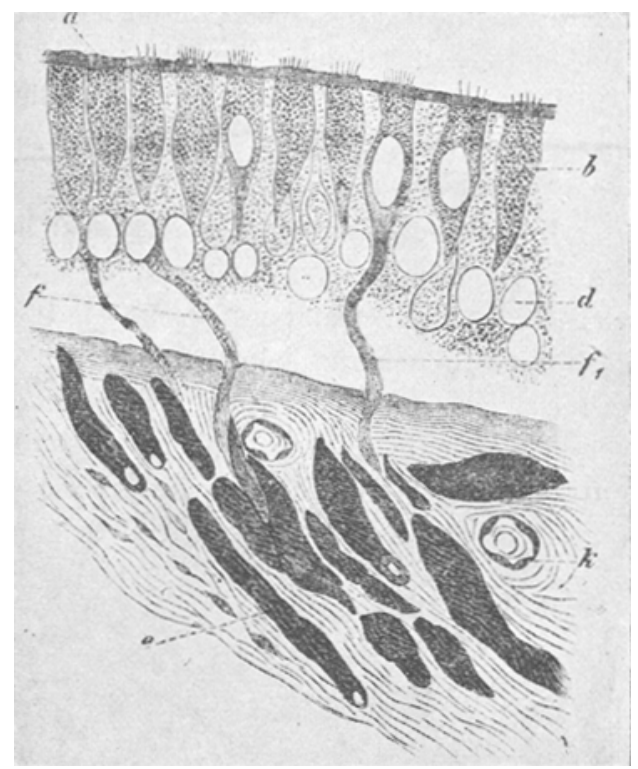

Fig. 20.

„einer Nervenendigung in der Schnecke den unmittelbaren Ueher„gang je einer ungetheilten marklos gewordenen Nervenfaser in den „basilaren Fortsatz der Haarzellen nachgewiesen. Ich kann nach ., eigenen Präparaten von der Taube seinen Angaken nur beipflichten; es sind hier ganz dieselben Verhältnisse wie bei den inneren Haarzellen der Säuger." auf die sich obige Figur bezieht.

Die Richtigkeit dieser Angaben ist in neuester Zeit mit verbesserten Methoden von $\mathrm{Rudolf} \mathrm{Krause}$ bestätigt worden. der sehr eingehende Studien an dem Gehörorgan der Cyclostomen an-

1) Hasse, De cochlea avium. Jiss. inaug. Kiliae 1\$66. - Göttinger Nachrichten 1867 Nr. 11. - Zeitschr. f. wissensch. Zoologie Bd. 17 \$. 56, 381, 461. 1867. Ibid. Bd. 18 S. 72, 359. 1868. Verhdlg. d. physik. med. Ges. Würzburg N. F. Bd. 1 S. 92.1868.

E. Pflüger, Archiv für Physiologie. Bd. 11:. 
gestellt und es sich besonders zur Aufgabe gemacht hat, die Beziehung der Neurofibrillen zu dem Protoplasma der Haarzellen festzustellen. An Schnitten, die durch die Crista geführt sind, beobachtete Krause ${ }^{1}$, dass die Nervenfaser sich immer an der Basis der Haarzelle „verbreitert in Form eines Bechers". Der nervöse Mantel kann sich hoch an der Zelle hinauf erstrecken. "Ma'n sieht "von der Zellbasis aus feinste Fädchen aus dem Nerven"kelch in den Zellkörper aufsteigen und in solchem "dicken Korn endigen". Ueber eine andere Stelle der Ampullen äussert sich Krause dahin: „Die Fasern treten, nachdem "sie die Membrana propria durchsetzt haben, immer auf dem „kürzesten Wege, und d. i. meistens senkrecht zur Epitheloberfläche, „an ihre zugehörige Zelle heran. Immer versorgt eine Faser auch „nur eine Zelle.

„Der Modus der Endigung ist genau so wie in den Cristae, „nur sind hier in vielen Fällen die aus dem Nervenbecher steigenden "Fibrillen leichter zu erkennen. Sie treten meines Frachtens fast „ausnahmslos nur in die Zellperipherie ein, bezw. liegen der Zelle "allerdings sehr dicht an.

Eine weitere Bestätigung des für uns wesentlichen Punktes, d. h. das Eindringen der Neurofibrillen in das Innere der Zelle, wurde von Walter Kolmer ${ }^{2}$ ) geliefert. Er lässt bei der Macula von Rana die Fibrillen seitlich in die Sinneszellen eindringen und im Innern der Zelle ein weitmasehiges Netzwerk bilden. Aehnliches ermittelte $\mathrm{K}$ olm er für die Haarzellen des Corti'schen Organes der Nager; der in die Haarzelle eingedrungene Nerv bildet ein Gitterwerk, das also innerhalb des Zellkörpers liegt. Krause ist mit diesem Gitterwerk nicht einverstanden. Wenn man die Präparate, welche Kolmer in seinen Abhandlungen mittheilt, genauer prüft, scheint mir seine Angabe berechtigt. Ich verweise hierbei auf den "Anatomischen Anzeiger" Bd. 26 S. 566 und Bd. 27 Taf. 13 (1905). Man muss doch immer in Betracht ziehen, wie gross der Einfluss

1) Rudolf Krause, Die Endigung des Nervus Acusticus im Gehörorgan des Flussneunauges. Kgl. Preuss. Akad. d. Wissensch., Sitzung 30. Nov. 1905. Sonderabdr. S. 19 u. 14.

2) Dr. Walter Kolmer, Ueber die Endigungsweise des Nervus octavus. Centralbl. für Physiol. Bd. 18 Nr. 20. 1904. - Ueber das Verhalten der Neurofibrillen an der Peripherie. Anatomischer Anzeiger Bd. 26 S. 560. 1905. Zur Kenntniss des Verhaltens der Neurofibrillen an der Peripherie. Ibidem. Bd. 27 S. 416. 1905. 
kleiner Verschiedenheiten in der mikroskopischen Technik ist. Im Uebrigén ist die Entscheidung der Frage, wie sich die intracellularen Fibrillen verhalten, für uns hier ohne Bedeutung.

Jedenfalls geht aus dieser Darstellung hervor, dass die Neurofibrillen des Acusticus in die Haarzellen eindringen, also intracellular endigen. Hier liegt doch wegen der Uebereinstimmung so vieler angesehener Forscher wissenschaftliche Sicherheit vor.

Abermals sehen wir Pbilipp Stöhr ${ }^{1}$ ) in getreuer Consequenz der Neuronenlehre verkünden, dass die Fasern des Nervus cochlearis zu den Iaarzellen ziehen, ,an (nicht in) denen sie enden“.
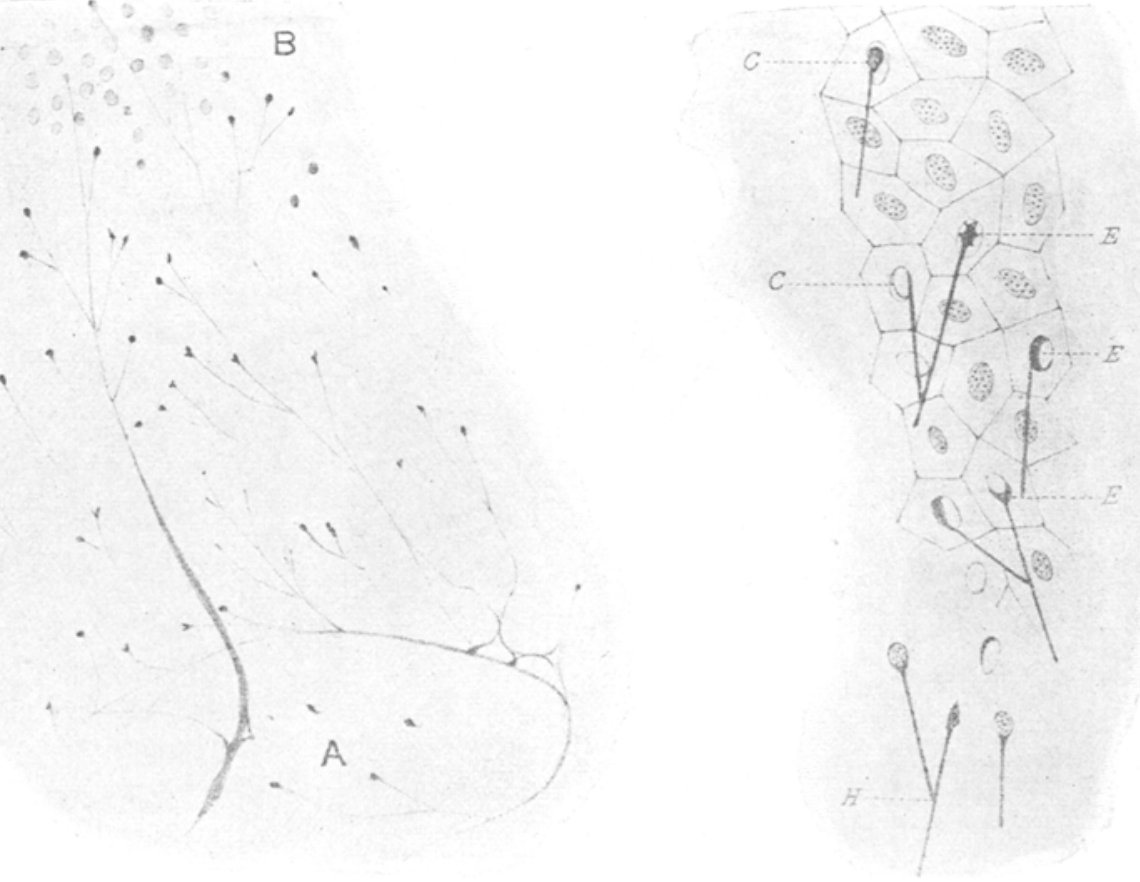

Fig. 21.

Ein schönes Beispiel für die intracelluläre Endigung sensibler Nerven in der Haut der Schildkröte entnehme ich einer Arheit von John Berry Haycraft ${ }^{2}$ ). Beifolgende Fig. 21 zeigt bei $A$ und

1) Philipp Stöhr, Lehrbuch der Histologie S. 405. 1905.

2) J. B. Haycraft, M. D. D. Sc. Terminations of Nerves in the Nuclei of the Epithelial Cells of Tortoisc-Shell.-Quaterly. Journal of Microscopical Science for November 1890. Sonderabdr. 
$B$ die Verästelung der Nervenfasern, welche in Knöpfchen auslaufen und bei $C, E, H$ mittelst stärkerer Vergrösserung die Enden der Nerven in den Zellkernen der Epithelien.

Ein anderes Beispiel entnehme ich der grossen berühmten Arbeit von Stefan Apathy ${ }^{1}$ ), dessen Präparat ich hier wiedergebe als

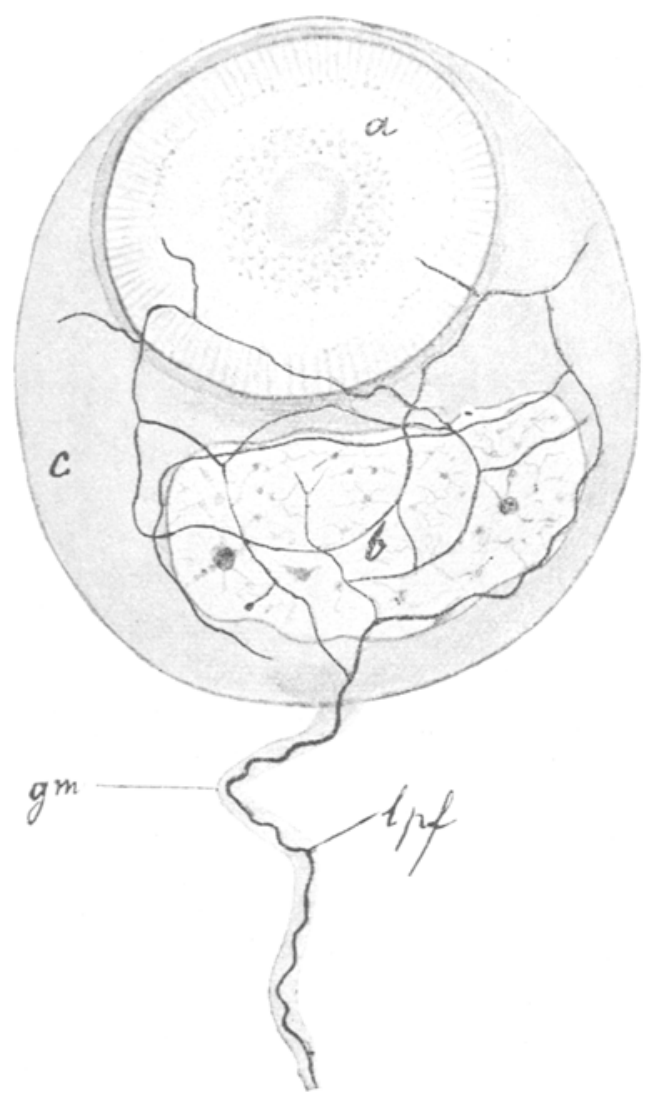

Fig. 22.

Fig. 22. Die Figur stellt „eine subepidermidale Sinneszelle (Retinazelle) von Pseudobranchellion" vor. $a$ Glaskörper, $b$ Zellkern, $c$ Zellkörper, $l p f$ leitende Primitivfibrille, welche in die Retinazelle eindringt und um den Zellkern ein Fibrillengitter bildet. Die Primitiv-

1) Stephan Apathy, Das leitende Element des Nervensystems und seine topographischen Beziehungen zu den Zellen. Mitth. a. d. zool. Station zu Neapel Bd. 12 S. 495 Taf. 31 Fig. 9. 1895-1897. 
fibrille ist vor dem Eintritt in die Retinazelle von einem perifibrillären Mantel $g m$ umhüllt, der bịs zum Eintritt der Fibrille in die Zelle reicht und dann aufhört. Vergrösserung 1500. (S. Apathy S. 747.)

Die mitgetheilten Thatsachen beweisen, dass in zahlreichen Fällen die Wechselbeziehung des Nerven und der Zelle durch unuterbrochenen organisirten Zusammenhang (Continuität) sich vollzieht, dass ferner kein Fall bekannt ist, der die Uebertragung der Erregung durch Contact beweist.

Die Anhänger der Neuronentheorie können erwidern, dass sämmtliche mitgetheilten Beispiele sich nicht auf den Wechselverkehr von Nervenzellen beziehen, die doch in erster Linie bei dem gegenwärtigen Streit in Betracht kommen. Auch diese Ausflucht ist leicht $\mathrm{zu}$ widerlegen.

Es ist der Ruhm St. Apathy's, wenigstens für die Wirbellosen bewiesen zu haben, dass die peripherischen und auch die centralen Ganglienzellen stetig mit einander durch Neurofibrillen zusammenhängen.

A pathy ${ }^{1}$ ) unterscheidet fünf verschiedene Arten der Anastomosen der Ganglienzellen. Die Untersuchungen beziehen sich wesentlich auf Pontobdella, Lumbricus, Hirudo. Für unsere Zwecke genügt es, die Eintheilung Apathy's zu vereinfachen und nur drei Arten der Zellenanastomosen zu unterscheiden:

I. Die Neurofibrille lässt sich aus einer Ganglienzelle in eine andere verfolgen.

II. In den Verlauf der verbindenden Neurofibrille ist ein Neurofibrillengitter eingeschoben, welches also Beziehungen zu anderen Ganglienzellen durch abtretende Aeste ermöglicht. Der einfachste Fall liegt vor, wenn von der die beiden Ganglienzellen verbindenden Neurofibrille ein Ast entspringt, der zu einer dritten Ganglienzelle verläuft.

III. Die zwei Ganglienzellen verbindende Anastomose lässt bei Apathy's Behandlung keine gefärbte Neurofibrille hervortreten. Meines Erachtens kann man der Anastomose deshalb nicht die Lejtungsfähigkeit absprechen. Denn A pathy selbst stellt in den 
Flimmerzellen gefärbte Neurofibrillen dar, welche mit einem ausserhalb der Flimmerzelle gelegenen gefärbten Neurofibrillennetz nicht durch gefärbte Neurofibrillen zusammenhängen.

Die Verbindung der extracellularen, färbbaren mit den intracellularen färbbaren Neurofibrillen wird also durch nicht färbbare Fibrillen vermittelt, wenn man die Continuität festhält und Apathy's Diagnose des intracellularen Pinsels anerkennt.

Das Verhalten der färbbaren Neurofibrillen in der centralen Ganglienzelle macht es mir auch im höchsten Grade wahrscheinlich; dass hier noch Vieles vorhanden ist, was die Methode Apathy's nicht zur Wahrnehmung bringt oder vielleicht geradezu auslöscht.

Dass in dem Nerven die Faser das Leitende ist und nicht der Saft, habe ich ${ }^{1}$ ) vor langer Zeit durch Thatsachen der Elektrophysiologie besser hewiesen, als es durch irgend eine andere Art bisher erzielt worden ist. Unter den Anatomen hat nur Oskar Schultze ${ }^{2}$ ) die Wichtigkeit meiner Beweisführung anerkannt. Albrecht Bethe ${ }^{3}$ ) beruft sich darauf, dass, wie das Nervenmark den Achsencylinder nicht überall bekleidet, so auch die Neurofibrillen nicht überall von der Perifibrillärsubstanz überzogen sind. "An den Ranvier'schen Einschnürungen der markhaltigen Wirbelthiernerven gehen nur die Primitivfibrillen vom Achsencylinder des einen Faches auf den des daranstossenden über, nicht die Perifibrillärsubstanz. Es ist nämlich an den Ranvier'schen Einschnürungen eine Platte unbestimmter Natur zwischen die beiden benachbarten Markscheidenfächer geschaltet, welche mit feinen Löchern durchsetzt ist, die nur gerade gross genug sind, um den Fibrillen den Durchtritt zu gestatten". Wie Bethe hervorhebt, ist diese Thatsache zuerst von Gustav Mann in der physiologischen Gesellschaft zu Oxford vorgetragen und in den Berichten der anatomischen Gesellschaft (Verhandlungen zu Kiel, Jena 1898) veröffentlicht worden. - Man kann gegen diese Beweisführung den Einwand erheben, dass die Neurofibrillen sicher oft nur Bündel von Elementarfibrillen darstellen, die durch eine interfibrilläre Substanz zusammengekittet sind.

1) E. Pflüg er, Die allgemeinen Lebenserscheinungen. Rectoratsrede. Bonn 1889.

2) Oskar Schultze, Die Continuität der Organisationseinheiten der peripheren Nervenfaser. Dies Archiv Bd. 108 S. 82.1905.

3) Albrecht Bethe, Die anatomischen Elemente des Nervensystems u.s. w. Biolog. Centralbl. Bd. 18 S. 856. 1898. 
Es ist nun doch möglich, dass es Elementarfibrillen von der alleräussersten Feinheit gibt. Alle Bearbeiter der Structur des Nervensystemes erkennen an, dass vielfach die Neurofibrillen bis zu unmessbarer Feinheit herabsinken. Dass wir keinen Anhalt zur Beurtheilung haben, ob eine Neurofibrille ein Bündel von Elementarfibrillen ist oder nicht, kann als sicher gelten.

Wenn man mit Osmiumsäure geschwärztes Oel in sehr feine Emulsion verwandelt, machen sich die feinsten Fettstäubchen unter dem Mikroskop nicht mehr durch ihre schwarze Farbe bemerkbar. Elementarfibrillen von höchster Feinheit werden also trotz der Färbung nicht mebr gesehen.

A pathy ${ }^{1}$ ) und Bethe ${ }^{2}$ ) sind der Ansicht, dass die Methode Golgi's nur solche Neurofibrillen schwärzt, welche einen Mantel von Perifibrillärsubstanz haben, weil nur diese, nicht die nervöse Fibrille gefärbt wird. Wenn nun die sehr feinen, nicht mehr nach Golgi färbbaren Neurofibrillen doch noch einen andersgearteten, dünnsten Mantel der Perifilorillensubstanz besässell, dem sie die Färhbarkeit nach A pathy verdanken, wäre es möglich, dass die allerfeinsten Elementarfibrillen, welche ganz frei von Perifibrillärsubstanz sind, auch nach Apathy's Methode nicht mehr dureh Färbung sichthar gemacht werden können. Mag man dies als unberechtigte Hypothese verurtheilen, berechtigt bleilit, nur Das zu glauben, was Apathy's Methode zur Anschauung bringt, unherechtigt aber, Alles zu leugnen, was sie uns nicht zu offenbaren vermag.

Man darf ferner in Betracht ziehen, dass der Mantel der Fibrillen bei der Färbung eine grosse Rolle spielt und nicht überall dieselbe Färbbarkeit besitzen muss. Abgesehen davon sprechen aber auch die specifischen Beziehungen gewisser Gifte zu bestimmten Nerven dafür, dass dic Natur der Neurofibrillen nicht überall dieselbe ist.

Sei dem wie ihm wolle. Wenn auch verschiedene Forscher schon vor A pathy die herrlichsten Anastomosen centraler Ganglienzellen bei Wirbellosen dargestellt haben, wie z. B. Dr. Georg Walter ${ }^{3}$, bei Wirbelthieren vor Allen Wagner und Besser.

1) Stefan Apathy, Die Mikrotechnik dbth. I s. 5 u. 193.1896.

2) A. Bethe, Die von M. v. Lenhossek gewünschten Aufklärungen. Neurol. Centralbl. Nr. 12. 1899.

3) Dr. Georg Walter, Mikroskopische Studien üler das Centralnervensystem wirbelloser Thiere. Bonn 1863 . 
die sogar von C. Golgi ${ }^{1}$ ), wenn auch als Ausnahmezustände anerkannt werden, so bleibt doch Stefan A pathy das grosse Verdienst, die Continuität des gesammten Nervensystemes wenigstens für die Wirbellosen durch seine Methode mit solcher Sicherheit festgestellt zu haben, dass jeder Widerspruch verstummen musste.

Wären lange und hartnäckig in der Wissenschaft gelehrte Irrthümer nicht so schwer zu beseitigen, so würde hiermit die Neuronentheorie endgültig vernichtet sein. Es bleibt aber noch immer unter den Anatomen, Klinikern und leider auch unter den Physiologen eine angesehene Partei, welche sogar mit dem berühmten Anatomen A. Köllike r uns entgegnet, dass, was für die Wirbellosen gelten mag, darum für die Wirbelthiere nicht bewiesen ist.

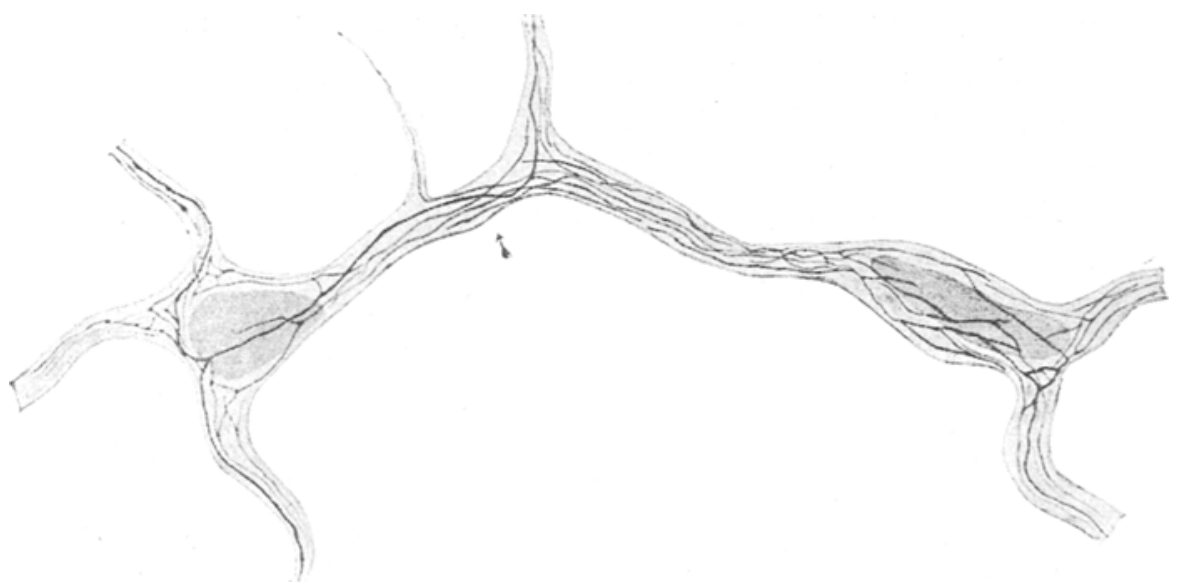

Fig. 23 .

Hier fällt desshalb schwer in das Gewicht, dass auch bei den Wirbelthieren die Anastomosen wenigstens zwischen peripherischen Nervenzellen doch ebenfalls über jeden Zweifel festgestellt worden sind.

Solche Nervennetze sind von C. Golgi2), A. S. Dogiel ${ }^{8}$ ),

1) Camillo Golgi, Untersuchungen über den feineren Bau des centralen und peripherischen Nervensystems S. 89. Jena 1894. - Wagner und Besser habe ich nach Golgi citirt, der näch beliebtem Gebrauch anf bibliographische. Nachweise verzichtet.

2) C. Golgi, Untersuchungen über den feineren Bau des centralen und peripherischen Nervensystems. (Aus dem Italienischen von Te u s ch er.) Jena 1894.

3) A. S. Dogiel, Die sensiblen Nervenendigungen im Herzen und in den Blutgefässen der Säugethiere. Arch. f. milkrosk. Anat. Bd. 52 S. 44.1898. 
A. Bethe ${ }^{1}$ ), O. Schultze ${ }^{2}$ ) dargestellt worden. Als Beispiel (Fig. 23) wähle ich zunächst ein Präparat von Bethe, welches zwei Zellen des subepithelialen Nervennetzes aus dem Gaumen vom Frosch darstellt (Methylenblaumethode). Die Neurofibrillen sind gut differenzirt und verlaufen von einer Nervenzelle zur anderen. - Figur 24 zeigt ein ebenfalls mit der Methylenblaumethode dargestelltes Nervennetz um eine kleine Arterie vom Frosch (nach Bethe).

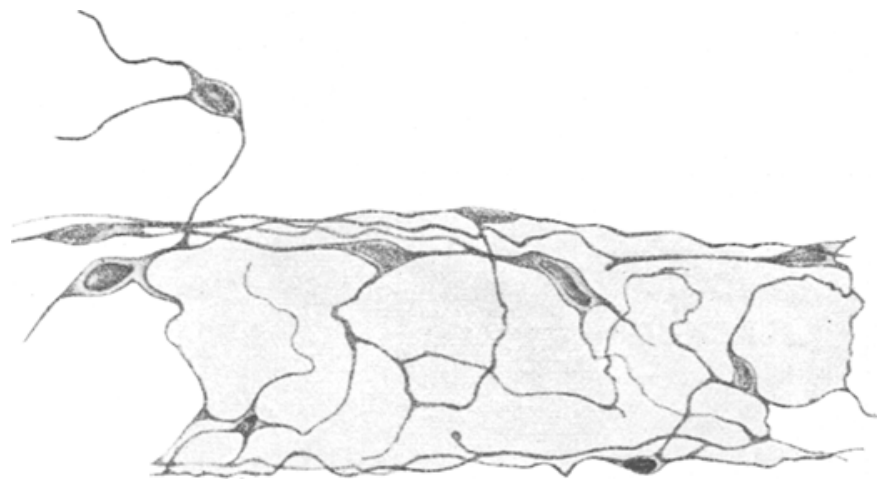

Fig. 24.

Wo also auch immer die Frage nach der Continuität oder Discontinuität des Nervensystemes durch die Gunst der Umstände zur sicheren Entscheidung gebracht werden konnte, wurde die Continuität bewiesen.

Es fragt sich nun, wie es wohl kommen mag, dass dieses unzweifelhaft auch für das centrale Nervensystem der Wirbelthiere geltende Gesetz bis jetzt durch die anatomische Zergliederung noch nicht mit wünschenswerther Sicherheit nachgewiesen werden konnte. Das deutet darauf hin, dass es mit den Anastomosen der centralen Ganglienzellen bei den Wirbelthieren eine besondere Bewandtniss haben muss.

Als Leitstern dient mir hier die grosse Entdeckung, welche Albrecht Bethe bei seinen physiologischen Versuchen am Carcinus maenas gemacht hat.

1) Albrecht Bethe, Allgemeine Anatomie und Physiologie des Nervensystems S. 78. Leipzig 1903. -.. Die Nervenendigungen im Gaumen und der Zunge des Frosches. Arch. f. mikrosk. Anat. Bd. 44 \&. 185.1895.

2) Oskar Schultze, Beiträge zur Hystogenese des Nervensystems. Arch. f. mikrosk. Anat. Ba. 66 s. 41. 1905. - Weiteres zur Entwicklung der peripheren Nerven. Phys. med. Gesellsch. Würzburg. N. F. Bd. 37 S. 267. 1905. 
Da es bei dieser Frage nicht auf die complicirten Verhältnisse des ganzen Versuches ankommt, will ich das Wesentlichste an der Hand eines von A. Bethe ${ }^{1}$ ) entworfenen Schemas (Fig. 25) erläutern, welches den Fibrillenverlauf im Nervensystem von Crustaceen darstellt. Bei dem Versuchsthier Carcinus maenas besteht das Bauchmark aus einer Anzahl dicht an einander gedrängter Ganglienpaare, welche durch kurze Längskommissuren mit einander verbunden sind. Bei diesem Thiere enthalten die einzelnen Ganglienknoten keine Ganglienzellen, sondern nur ein Flecht- und Netzwerk von Neurofibrillen, welches als Neuropilem bezeichnet wird.

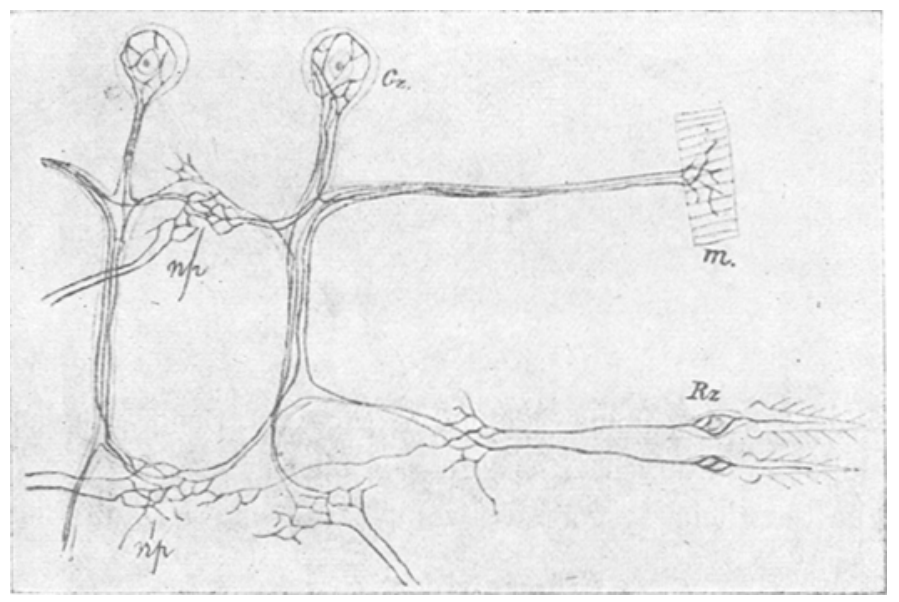

Fig. 25 .

(Fig. $25 n p$.) Aus diesem Neuropilem entspringen Empfindungsnerven, welche zu der Sinneszelle $R \varepsilon$, und Bewegungsnerven, welche zu dem Muskel $m$ in Beziehung stehen. Die eigentlichen langgestielten unipolaren Ganglienzellen $g z$ sitzen wie Beeren auf dem Ganglienknoten, der also selbst nur das Neuropilem enthält. Bethe wählte für seinen Versuch den Ganglienknoten der zweiten Antenne von Carcinus maenas. Wird der Nerv der zweiten Antenne durchschnitten, so ist die Antenne dauernd gelähmt. „Während sie "normalerweise schräg nach vorne gehalten wird, hängt sie jetzt "schlaff herab; während sie sonst auf jede Berührung hin sofort ein-

1) Albrecht Bethe, Allgemeine Anatomie und Physiologie des Nervensystems S. 99.1903. 
„gezogen wird, kann man sie nach der Durchschneidung der Nerven „so stark reizen, wie man will, sie bleibt bewegungslos". Sicherlich ist also das "Centrum" der Antennenbewegung im centralen Nervensystem gelegen. Bethe trug nun die Ganglienzellen auf der Oberfläche des betreffenden Ganglienknotens mit Hilfe eines winzigen Messers ab und durchschnitt die Verbindung desselben mit dem Gehirn- und Bauchmark. „Es hängt also mit dem Nerven "der zweiten Antenne nur noch ein Stück Neuropil zusammen, das "frei von Ganglienzellen ist."

Unmittelbar nach der eingreifenden Operation ist eine allgemeine Paralyse des Thieres vorhanden. Aber schon einen Tag nach der Operation stellen sich die Reflexe wieder ein. „Die Antenne hängt dann nicht mehr sehlaff herab, wie nach Durchschneidung des Nerven. sondern wird in der normalen Lage gehalten. Der Tonus ist also vorhanden. Beim Berühren wird die Antenne flectirt und tann wie bei einem normalen Thier wieder vorgestreckt. Die Reflexerregbarkeit ist also ebenfalls erhalten. Setzt man hintereinander mehrere schwache, an sich unwirksame Reize an. so tritt ein Reflex ein. Das ganglienzellenlose Neuropilstück ist also noch der Reizsummation fähig. Als einziger Unterschied gegen ein normales Thier zeigte sich eine wesentliche Erhöhung der Reflexerregbarkeit. In den nächston Tagen nach der Speration nimmt die Reflexerregbarkeit immer mehr ab und ist am vierten 'Tage ganz crlosehen, was nach dem schwercn Fingriff verständlich ist, und dem Versuche nicht seinen hohen Werth raubt. A. Bethe schliesst: .. Die Ganglienzellen sind also zu den wesentlichsten Erscheinungen des Centralorgans nicht nothwendig".

Die grossartige Leistung Albrecht Bethe's hat die verdiente Anerkennung vielfach nicht gefunden. und unter den Physiologen ist nur Friedrich Schenck ${ }^{1}$ ) in rühmlicher Weise für Bethe eingetreten.

Es ist doch die Wahrheit, dass wir immer die geheimnissvollen Thätigkeiten der nervösen Centralorgane in diejenigen Bildungen verlegt haben, welche Ganglienzellen oder Nervenzellen genannt werden. Das räthselhafte Fasergewirr, welches die Räume zwischen

1) F. Schenck, Die Bedentung der Neuronenlehre für die allgemeine Nervenphysiologie. Würzburger Abhandlungen aus dem Gesammtgebiet der praktischen Medizin Bd. 2 S. 183. 1902. 
den Ganglienzellen ausfüllte, wurde betraut mit der Herstellung der Leitungsbeziehungen. Albrecht Bethe hat aber bewiesen, dass in den Räumen dieses Fasergewirres Gewebe der ungewöhnlichsten Bedeutung lagern, weil sie Träger der höchsten Functionen des Nervensystemes sind. Für die Existenz solchen Gewebes höchster Bedeutung, für das sogenannte "nervöse Grau", hat schon der um die Lehre von der elementaren Structur des Nervensystems so sehr verdiente $\mathrm{Nissl^{1 }}$ ) auf das Eifrigste gekämpft.

Für diejenigen, welche gleich mir von dem continuirlichen Zusammenhang aller Nervenzellen überzeugt sind, erscheint das gesammte Nervensystem als ein Syncythicum, das die verschiedensten Differentiationen an verschiedenen Orten erfabren hat. Wie alle von Fortsätzen der Ganglienzellen reden, die sie aus Protoplasma bestehen lassen, wenn sie auch als feinste Fasern auftreten, so halten wir das Neuropilem oder das nervöse Grau für Zellsubstanz, deren feinere Structur bis jetzt zu enträthseln noch nicht gelungen ist. Albrecht $B$ eth $\mathrm{e}^{2}$ ) hat in seiner Vertheidigung gegen die unberechtigte Herabsetzung der Bedeutung seines Versuches bereits dieselbe Auffassung begründet. Mag nun das zwischen den Ganglienzellen liegende Fasergewirr als Zellsubstanz gelten müssen, Niemand hat geahnt, dass gerade in dieser Art Zellsubstanz diejenige Function auch ihr Substrat hat, welche wir bisher allein in die Ganglienzelle verlegten. Ich für mein Theil bin nun überzeugt, dass ausser den allbekannten Neurofibrillen im Neuropil noch eine andere Zellsubstanz existirt, d. h. ein nur aus wenigen Molekülen bestehendes Mikropilem höherer Ordnung, welches durch die mikroskopische Technik vielleicht niemals sichtbar gemacht werden kann.

Wie Stefan Apathy ${ }^{3}$ gezeigt hat, werden die Wechselbeziehungen der centralen Ganglienzellen bei den Wirbellosen wesentlich durch das Neuropilem vermittelt. Wenn dasselbe auch für die Wirbelthiere gilt, wird die Schwierigkeit des Nachweises des continuirlichen Zusammenhanges der Ganglienzellen unter einander sofort begreiflich. Alles spricht dafür, dass hierin die Lösung des Räthsels liegt.

1) Franz Nissl, Die Neuronenlehre und ihre Anhänger S. 444. Jena 1903.

2) Albrecht Bethe, Die anatomischen Elemente des Nervensystems. Biolog. Centralbl. Bd. 18 S. 843. 1898.

3) Stefan Apathy, Das leitende Element des Nervensystems und seine topographischen Beziehungen zu den Zellen. Mittheilungen aus der Zoologischen Station zu Neapel Bd. 12 S. 638. 1895-1897. 
Die bedeutungsvollen Entdeckungen, welche Camillo Golgi gemacht, und die Erklärungen, welche er auf Grund derselben über die Wechselbeziehungen der centralen Ganglienzellen gegeben hat, genügen bis zu einem gewissen Grade vollkommen zum Verständniss und fügen sich in harmonischer Weise in unsere Anschauungen über die Art der Fortpflanzung des Nervenprincips durch die nervöse Substanz.

Drei Sätze sind nach Golgi ${ }^{1}$ ) zu beachten:

1. Der Achsencylinder eines markhaltigen motorischen Nerven setzt sich als solcher und ohne Unterbrechung in den Achsencylinderfortsatz der centralen motorischen Ganglienzelle fort. „Directe "Endigung Grolgi" oder Typus I.

2. Der markhaltige sensible Nerv wird mit dem Achsencylinderfortsatz der sensiblen centralen Nervenzelle durch Einsebaltung von Neuropilem verknüpft, aber ohne Unterbrechung der Continuität der Neurofihrillen. „Indirecte Fndigung Golgi" oder Typus II.

3. Der motorische Achsencylinderfortsatz gibt Seitenäste al). welche durch vielfache Verästelung auch ein Neuropilem hilden, das mit dem der sensiblen Faser continuirlich zusammenhänot. Die Anastomose zwischen beiden Ganglienzellen ist also keine Faser, sondern ein Fibrillennetz.

Nach dieser Vorstellung sind es die Verästelungen der Achsencylinderfortsätze, welche die centralen Ganglienzellen unter einander verknüpfen, ein Verhalten, welches bei den Wirbellosen im Wesentlichen nachgewiesen ist.

Bei den Protoplasmafortsätzen konnte C. Golgi werer Anastomosen noch Uebergänge in ein Neuropilem nachweisen und betrachtet dieselben als Ernährungssorgane. Alles spricht gegen die Richtigkeit dieser Auffassung. Bei keiner Zellenart von lebhaftestem Stoffwechsel, wie z. B. den Muskeln, sieht man eine so nnçeheure Zerfaserung der Masse, um dem starken Verbrauch an Sauerstoff und Nährstoff zu genügen. Die erstaunliche Länge und Verdünnung der Protoplasmafortsätze würde wegen der Langasamkeit der Diffusionsströıne, z. B. für den Transport des Sauerstoffs, aber auch der Nährr-

1) Camillo Golgi. Ueber die feinere Anatomie der Centralorgane des Nervensystems, in: Untersuchungen über den feineren Bau des centralen und peripherischen Nervensystems von Camillo Golgi (Deutsch von R. Teuscher) s. 100.1885. 
stoffe nach dem Zellenkörper, die denkbar unzweckmässigste Einrichtung sein. Ausserdem hat doch der Protoplasmafortsatz dieselben Neurofihrillen wie der Körper der Ganglienzelle selbst, sodass kein Grund vorliegt, der Substanz der Protoplasmafortsätze eine andere Bedeutung zuzuschreiben als der Ganglienzelle. Das wird ferner erhärtet durch den Umstand, dass nach Otto Deiters (a. a. O. Taf. II) aus sehr feinen Protoplasmafortsätzen, weit entfernt vom Körper der Ganglienzelle, feine Achsencylinderfortsätze entspringen, die in markhaltige Nerven ubergehen. Deiters war ein zu genauer Beobachter, als dass man diese Verbältnisse todtschweigen dürfte, wie es heute meist beliebt wird, weil es nicht in den Kram passt. Die Achsencylinderfortsätze zweiter oder höherer Ordnung sind schwer nachweisbar, und ich glaube, dass dieser Punkt neue eingehende Untersuchungen wünschenswert erscheinen lässt. Die Seitenäste der Achsencylinderfortsätze sind ja auch wegen der Schwierigkeit ihres Nachweises viele Jahre lang allgemein nicht gesehen worden, bis eine geeignete neue Technik plötzlich sichtbar machte, was bis dahin nicht zu existiren schien. - Ich möchte deshalb aber nicht leugnen, dass alle Achsencylinderfortsätze sich doch functionell von den Protoplasmafortsätzen unterscheiden. Wenn man sieht, dass, wie C. Golgi selbst sagt (a. a. O. S. 92), „die Protoplasmafortsätze sich "zum allergrössten Theile nach der freien Oberfläche der Windungen "(der Hirnrinde) zu richten, wo in der Regel gar keine Nervenfasern "vorhanden sind“, wenn man, fahre ich fort, die zahllosen Verästelungen der feinsten Protoplasmafortsätze gerade die Rinde des grossen und kleinen Gehirnes aufsuchen sieht, drängt sich der Gedanke auf, dass sie zum materiellen Substrat der psychischen Function in Beziehung treten, ja dass vielleicht ihre letzten Ramifikationen oder sie selbst dieses Substrat darstellen. Vielleicht sind die Achsencylinderfortsätze mehr für die Leitung, die Protoplasmafortsätze für die centrale Arbeit der psychischen Processe bestimmt.

Wenn C. Golgi ein besonderes Gewicht darauf legt, dass die Protoplasmafortsätze mit Bindegewebszellen und Blutgefässen in nähere Beziehung treten, so spricht dies nicht gegen die hohe Bedeutung dieser Fortsätze, weil diese als Theile einer Ganglienzelle von durchaus anderer Natur wie eine Bindegewebszelle sind und bleiben, wenn sie auch beim Wachsen gegeneinander gepresst werden, um den Schein der Verschmelzung zu erwecken, was ja doch auch nur ausnahmsweise vorkommt. 
Die untergeordnete Bedeutung, welche C. Golgi den Protoplasmafortsätzen im Gegensatz zu den Achsencylinderfortsätzen zuschreiben will, steht in Widerspruch mit der Thatsache, dass die Masse der Achsencylinderfortsätze von der der Protoplasmafortsätze scheinbar bei Weitem übertroffen wird. Thatsächlich kann man sehr oft es als fast sicher bezeichnen, dass die Masse der Protoplasmafortsätze einer Ganglienzelle der grossen Hemisphären oder des kleinen Gehirnes bei Weitem sogar die Masse des Körpers der Ganglienzelle übertrifft. Nicht selten lässt sich eine Pyramidenzelle der grossen Hemisphären annähernd einer ungeheuer langen, aber sehr dünnen Pyramide mit sehr kleiner Basis vergleichen, so dass gar keine Abgrenzung von Körper und Fortsatz der Ganglienzelle vorhanden ist. Sofort sieht man, dass ein und dieselbe Substanz die dünneren und die dickeren Theile der Pyramide darstellt. Ich glaube also, dass die diesen Pyramidenzellen angehörige Zellsubstanz in ihrer Gesammtheit, also mit Einschluss ihrer Verästelungen, zu denen wohl das nervöse Grau gehört, das Substrat der psyehischen Vorgänge in centralen Nervensysteme ausmacht.

Bei diesen Fragen möchte ich das Augenmerk auf dic von ten Histologen hesonders in neuerer Zeit zu wenig heachtete Thatsache hinweisen, dass zwei Vorgange ganz versehiedener Art im Nervensysteme gleichzeitig vorhanden sind. Dass der eigentliche psychische Process: Empfindung, Gedanke, Wille, eine Erregungsform anderer Art ist als die Fortpflanzung der Reizung durch einen peripherisehen und wohl auch centralen markhaltigen Nerven, ist doch wohl kanm zu bezweifeln. Dass diese beiden versehiedenen Vorgänge an verschiedene materielle Substrate gebunden sind, ist desshalb ebenfalls im höehsten Grade wahrscheinlich. Weil aber aberall da, wo die psychischen Voroänge auftreten, die Substanz der sogenannten Ganglienzellen auftritt, muss man an der alten Annahme festhalten, dass eine eigenthümliche Art Zellsubstanz das Substrat der psychischen Vorgänge ist. Weil in den letzten Jahren der selbstverständlich hochwichtige Nachweis des Verlaufs der Neurofibrillen in ausrezeichnetster Weise gehungen ist, stellen einige Histologen und wie mir scheint besonders Stefan Apathy die Structur des Nervensystemes so dar, als sei die Neurofibrille der wesentliche Theil und die Substanz der Ganglienzelle entweder nur eine gleichgültige Anlagerung oder ein Ernährungsorgan jener Neurofibrillen. Nein! ich glaube wahr wird bleiben, was die alten Physiologen immer an- 
nahmen: das Nervensystem besteht aus zwei Substanzen: Achsencylinder einerseits und Substanz der Ganglienzelle andererseits.

C. Golgi ist durch die wichtigen Thatsachen, welche er über den Verlauf der Nervenfasern in den Centralorganen festgestellt hat, $\mathrm{zu}$ physiologischen Schlussfolgerungen veranlasst worden, die ich nicht mit Stillschweigen bei dieser Gelegenheit übergehen will. Denn $\mathrm{er}^{1}$ ) behauptet, dass dem Gesetze der isolirten Leitung jede anatomische Grundlage entzogen sei. In der That liegt die unerwartete Thatsache vor, dass die sensible Nervenfaser nach dem Eintritt in das Rückenmark, ehe sie mit irgend einer Ganglienzelle in Beziehung tritt, sich in eine mehr oder weniger grosse Zahl von Aesten spaltet, die nach verschiedenen Richtungen weiter ziehen. Diejenigen, welche an der orthodoxen Lehre festhalten, dass nur im Gehirne Empfindung ist, können sich denken, dass von jenen durch Theilung im Rückenmark entstandenen Nervenfasern Alle, ausser einer Einzigen, zur Reflexfunction des Rückenmarks bestimmt sind. Jene Einzige zieht aber nach dem Gehirn, um dort mit einer Ganglienzelle in Verbindung zu treten. Da nun Golgi annimmt, dass diese Empfindungsfaser nicht direct mit der Ganglienzelle sich verknüpft, sondern unter Vermittlung des Neuropilems, so ist zu beachten, dass er ${ }^{2}$ ) selbst es ausdrücklich dahingestellt sein lässt, ob dieses ein Netz von Fibrillen oder ein Flechtwerk derselben ist. Handelt es sich um ein Flechtwerk, so setzt sich also die Empfindungsfaser ohne Unterbrechung bis zum Achsencylinderfortsatz der sensiblen Ganglienzelle fort. - Wäre das Neuropilem scheinbar ein wirkliches Netz von Neurofibrillen, so kann Niemand sagen, ob diese nicht Bündel von Elementarfibrillen sind, also in Wahrheit auch nur ein Flechtwerk. Nimmt man an, dass die Empfindung schon im Rückenmark nach Reizung eines Empfindungsnerven der Haut entsteht, so bleibt die Erklärung dieselbe. Es ist also die Zerfaserung des sensiblen Nerven und seine Einmündung in das Neuropilem durchaus mit der Annahme der isolirten Leitung verträglich. Was sollte sonst die Markscheide der zahllosen Gehirnnerven, ja sogar die perifibrilläre Substanz der Neurofibrillen bedeuten, wenn es sich nicht um die

1) C. Golgi, a. a. O. S. 101 u. 104.

2) C. Golgi, a. a. O. S. 95. 
Sicherung der isolirten Leitung des Nervenprincipes handelte. Die grossen, nicht nervösen Fettmassen des Gehirnes, die bis zum Hungertode dem Angriff des Sauerstoffs widerstehen, weil sie absolut nothwendig sind, wären ganz und gar unbegreiflich.

C. Golgi glaubt nun nach seinen Präparaten eigentlich zu der Annahme berechtigt zu sein, dass das Neuropilem eher ein Netz von Neurofibrillen als ein Flechtwerk derselben darstellt. Bei dieser Vorstellung macht die Erklärung der Ortempfindung der Haut u. s. w. mehr Schwierigkeit.

Weil es Thatsache ist, dass wir den Ort verschiedener Hautreize, die noch so gleichartig sind, doch richtig beurtheilen, müssen die vou verschiedenen Hautstellen ausgehenden Empfindungen eine Verschiedenheit haben, ein "Localzeichen". Desshalb denke ich mir, dass da, wo der Empfindungsnerv sich an der ihm zugehörigen Stelle des Neuropils aufsplittert, eine nur ihm zukommende Erregungsart entsteht, die wie eine hesondere Melodic sich nun durch das Neuropil fortpflanzt wie die Musik durch die Luft. Jedem Endigungspunkt der verschiedenen sensiblen Nerven entspricht eine andere Melodie, die für ihn charakteristisch ist und welche eine bestimmte Provinz des Neuropilems erregt. - Es ist denkbar, dass für jede Melodie besoudere Leitungsfasern, gleichsam nur auf sie abgestimmte Resonatoren, aus den verschiedenen Provinzen des Neuropilems die verschiedenen Zeichen der Gehirnrinde zuführen. Dies Alles ist nicht im Widerspruch mit dem Geset\% der isolirten Leitung. - In ähnlicher Weise kann man sich die vom Gehirn ausgehende motorische Imnervation zurecht legen. Ich habe mir die Executive immer so gedacht, wie die Beherrschung der Bewegung einer grossen Armee. Der Oherbefehlshaber sendet seine Weisungen an die Generale der Armeekorps, diese an die Regimentscommandeure u. s. w. Denn in dem centralen Nervensystem sind, meiner Ansicht nach, Reihen über- und untergeordneter psychischer Centren.

Das Ergebniss, zu dem wir gelangten, liegt also in der Ueberzengung, dass die Neuronenlehre, soweit sie auf anatomischer Basis stand, nicht mehr aufrecht erhalten werden kann, was ja auch von hervorragenden Neurologen wie z. B. Ludwig Edinger ${ }^{1}$ ) anerkannt wird. Wenn man bedenkt, dass eine so grosse Autorität

1) L. Fudinger, Vorlesungen über den Ban der nervösen Centralorgane u. s. w. Vorlesung 2 n. 3. 1904.

E. I'tluger, Arrhiv tür Physiolugie. Bd. 11: 
wie Albert Kölliker, der sich so ausserordentliche Verdienste um die Erkenntniss der Structur des Nervensystemes erworben bat, noch in dem vergangenen Jahre die Neuronenlehre mit solcher Schärfe als alleinige Wahrheit verkündet hat, kann man den Heissspormen unserer Partei nicht beipflichten, wenn sie die Neuronenlehre als einen abgethanen Irrthum bezeichnen. Auch ich habe lange nicht daran glauben wollen, dass diese Irrlehre sich eines so grossen Beifalls für so lange Dauer erfreuen könne.

Das grosse Verdienst, die richtige Erkenntniss gesichert $\mathrm{zu}$ haben, gebührt Stephan Apathy, Franz Nissl, Albrecht Bethe, Oskar Schultze, Hermann Joris.

Man sucht aber jetzt die Neuronenlehre unter veränderter Form neu zu beleben. Hiernach bilden die centralen Nervenzellen zwar ein ohne Unterbrechung in sich zusammenhängendes Netz. Jede Zelle regelt aber in ihrem Bezirk die Ernährung und stellt eine trophische Einheit dar - ein Neuron.

Die Berechtigung dieser neuen Fassung der Neuronenlehre ist in hohem Grade zweifelhaft. Die Stütze derselben liegt in der Behauptung, dass die Zerstörung der Ganglienzellen ein Absterben der aus ihuen entspringenden Nervenfasern und Fortsätze bedinge.

Wie schwierig die Deutung der für die trophischen Einheiten beigebrachten Thatsachen ist, folgt daraus, dass die Spinalganglien, welche als classische Beispiele von Ernährungscentren der sensiblen Nerven und der Hinterstränge des Rückenmarks gelten, vollkommen exstirpirt werden können, ohne dass jedesmal nach einer Reihe von Monaten eine Entartung der hinteren Wurzeln und Stränge des Rückenmarks sich vollzogen hat. Der merkwürdige Versuch ist von Albrecht Bethe $^{\mathbf{1}}$ ) so beim jungen Hunde ausgefüht, dass auf der linken Seite sechs Spinalganglien exstirpirt wurden. Bethe hebt hervor, dass er die exstirpirten Spinalganglien als Beweisstücke aufbewahrt habe. Die fünf Monate später ausgeführte Section ergab normale hintere Wurzeln und Hinterstränge. Dieser einzige Versuch widerlegt die trophischen Centren. Wie B ethe getäuscht sein sollte, ist nicht abzusehen, wohl aber zu erwarten, dass der Versuch todtgeschwiegen wird. Der Versuch hat ein so grosses Gewicht, weil

1) Albrecht Bethe, Allgemeine Anatomie und Physiologie des Nervensystems B. 208. 1903. 
Albrecht Bethe durch die- unbedingte Zuverlässigkeit seiner Beobachtungen nicht bloss von seiner Partei, sondern auch von seinen Gegnern anerkannt wird, wie z. B. von A. van Gehu chten ${ }^{1}$ ), einem der hervorragendsten und entschiedensten Vertreter der Neuronentheorie, welcher die Präparate Bethe's mit dessen Beschreibungen verglichen und die in jeder Beziehung vorhandene Uebereinstimmung bezeugt hat. A. van Gehuchten sagt: "Nous tenons à déclarer que ses descriptions concordent en tous points avec ses préparations."

Ein Forscher, welchem es gelänge, die Bedingungen zu ermitteln, von denen das Gelingen des Versuches von A. B ethe abhängt, würde sich ein grosses Verdienst erwerben.

Eine andere Ironie liegt darin, dass die Ganglienzelle, welche das Ernährungscentrum des aus ihr entspringenden motorischen Nerven darstellen soll, selber abstirbt oder degenerirt, wenn dieser Nerv zerstört wird, als ob er umgekehrt die ernährende Wurzel der motorischen Ganglienzelle wäre. Wenn die auf einen compacten Klumpen zusammengedrängte Masse der Ganglienzelle ohne ihren Nerven langsamer abstirbt, als die in unendlich feine Fädchen zerklüftete Masse des peripherischen Nerven ohne seine Ganglienzelle, so ist als nächste Schlussfolgerung nur die Annahme berechtigt, dass in diesen Unterschieden verschiedene Grade derselben Störungen vorliegen. Solange die nach verschiedenen Verwundungen einzelner Theile des Nervensystems auftretenden Entartungen nicht unter einen allgemeinen Gesichtspunkt gebracht werden können, darf von einem Verständniss nicht die Rede sein. -

Die Neuronenlehre sieht in den nach der Verwundung auftretenden Entartungen die Folgen, welche sich an die Störung der trophischen Thätigkeit der Ganglienzelle knüpfen.

Wenn man von einigen gelegentlichen Beobachtungen früherer Zeit absieht, scheint dieses für Physiologie und klinische Medicin wichtige Gebiet wesentlich durch die grosse Entdeckung Dickin son's ${ }^{2}$ ) eröffnet: Degeneration der Nervenstümpfe und Nerven-

1) A. van Gehuchten, Considérations sur la structure interne de la cellule nerveuse et sur les connexions anatomiques des neurones. Brlletin de l'Acad. de Médecine de Belgique [4] t. 18 p. 28.1904.

2) W. H. Dickinson, On the Changes in the Nervous System which follow the amputation of Limbs. Journal of Anatomy and Physiology vol. 3 p. 88.1869. 
centra a mputirter Glieder. Bestätigt wurden diese Thatsachen durch Dickson ${ }^{1}$ ), Hayem ${ }^{2}$ ) und A. Gilbert ${ }^{3}$ ).

Dasselbe Gebiet ist dann von einem neuen Gesichtspunkte aus durch den genialen Bernhard v. Gudden $n^{4}$ zu einer der werthvollsten Fundgruben zur Entzifferung der Structur des Gehirns ausgebildet und durch seine Schüler, besonders August Forel ${ }^{5}$ ), weiter bereichert worden. Von Letzterem stammen die uns hier besonders interessirenden beiden Gesetze:

„1. Der motorische Nerv degenerirt auch beim Erwachsenen „doppelseitig und mit seinen Ursprungszellen, wenn er, „wie bei B. Gudden's Verfahren an Neugeborenen, an der Hirn"basis durchtrennt wird.

"2. Durchschneidung des motorischen Nerven in „seinem peripherischen Verlauf, wenn eine genügende Dis„location das Nachwachsen des centralen Stumpfes bis zum Muskel "verhindert, hat eine sehr langsame marantische Verkleine${ }_{\text {}}$ rung der Fasern des centralen Stumpfes und ihrer Ur„sprungszellen zur Folge, wie es schon Hayem und Andere "fanden."

In neuerer Zeit hat sich $\mathrm{Franz} \mathrm{Niss}^{6}$ ) durch die ausserordentliche Verfeinerung der mikroskopischen Technik zum Nachweise der nach Verletzungen peripherischer Nerven sehr bald in den centralen Ganglienzellen auftretenden Entartungserscheinungen ein grosses Verdienst erworben.

1) Dickson, Transactions of Pathological Society vol. 24. London 1873. Das Original konnte ich mir nicht verschaffen (P.).

2) G. Hayem, Lésions des Nerfs des Membres consecutives à l'amputation. Bullet. de la Société anat. 1875. - Derselbe, ibidem 1876.

3) G. Hayem, und A. Gilbert, Note sur les Modifications du Systeme Nerveux chez un amputé. Arch. de Physiol. [3] t. 3 p. 430.1884.

4) Bernhard von Gudden, Gesammelte und hinterlassene Abhandlungen, von H. Grashey herausgegeben mit wertvollem Nekrolog. Wiesbaden 1889 .

5) August Forel, Einige hirnanatomische Betrachtungen und Ergebnisse, Arch. f. Psychiatrie Bd. 18 S. 195.1886.

6) Franz Nissl, Ueber die Veränderung der Ganglienzellen am Facialiskern des Kaninchens nach Ausreissung des Nerven. Allgem. Zeitschr. f. Psychiatrie Bd. 48 S. 197. 1891. - Derselbe, Ueber experimentell erzeugte Veränderungen an den Hornzellen des Rückenmarks bei Kaninchen. Allgemeine Zeitschrift für Psychiatrie Bd. 48 S. 675. 1892. — Derselbe, Ueber eine neue Untersuchungsmetbode des Zentralorganes speciell zur Feststellung der Localisation der Nervenzellen. Neurolog. Centralbl. Bd, 17 S. 337. 1894. 
Das in physiologischer und klinischer Beziehung hoch wichtige Gebiet, welches wir hier nur berührt haben, möchte ich charakterisiren durch den Begriff der Reactionen des Nervensystems auf Substanzverluste.

Es fehlt an einer ausreichenden Zahl von Untersuchungen, welche die Grundgesetze dieses Gebietes festzustellen gestatten.

Ich verschiebe deshalb die Ausarbeitung des Teiles II dieser Abhandlung, bis gewisse, jetzt schwebende Streitfragen ihre Erledigung gefunden haben.

\section{Das Ergebniss.}

D) as gesammte Nervcnsystem mit den unter seiner unmittelbaren Herrschaft stehenden Organen stellt ein untheilbares System dar: ein Individum - und besteht nicht aus einer Vielheit getrennter Einzel. wesen. Will man das hier Wesentliche durchein Bild veranschalichen, so ist das Nervensystem mit Einschluss seiner Endorgane einer Stahlglocke vergleichbar und nicht einem Haufen Stahlstaub, der dureh Pulverisation der Glocke hergestellt worden ist. 